\title{
Thermal monitoring of a concrete bridge in London, UK
}

David T. Nepomuceno MEng (Bris)

Doctoral student, University of Bristol, Bristol, UK (Orcid:0000-0001-5612-1176)

Graham T. Webb MEng, MA (Cantab), PhD (Cantab), CEng, MICE Principal Engineer, WSP, London, UK

John Bennetts MA (Cantab), MSc (Sur), EngD (Bris), CEng, MICE

Associate, WSP, Bristol, UK

Theo Tryfonas PhD (Athens), FRSA

Associate Professor of Smart Cities \& Urban Innovation, Department of Civil Engineering, University of Bristol, Bristol, UK (Orcid:0000-0003-4024-8003)
Paul J. Vardanega BE, MEngSc (QIdUT), PhD (Cantab), GMICE, MASCE, MIEAust, FHEA

Senior Lecturer in Civil Engineering, Department of Civil Engineering,

University of Bristol, Bristol, UK (Orcid:0000-0001-7177-7851)

(corresponding author: p.j.vardanega@bristol.ac.uk)

During bridge design and assessment, effects of thermal actions are accounted for by means of a uniform temperature variation and temperature difference components. The uniform temperature variations cause changes in length and width of the structure, whereas the temperature difference components primarily cause curvatures and internal stresses. The effects of these strains on the superstructure depend on the structure's articulation and restraint. Design profiles used to model the temperature difference components vary between design codes, which can have a significant effect on the induced curvatures. Thermal data findings obtained from a comprehensive, yearlong monitoring programme on Waterloo Bridge in London are examined, which allows comparison of these various models with performance data. The design thermal model in BS EN 1991-1-5 is examined, supplemented by the models from the Aashto and New Zealand codes. The measured uniform bridge temperature generally fell within the stipulated limits of BS EN 1991-1-5; however, at low temperatures the minimum deck temperature may be lower than the design relationship provided. The resultant moments implied from the measured vertical profiles: significantly exceed the worst-case values predicted by the UK model; exceed the Aashto model at different bridge sections; and do not exceed the New Zealand model.

\section{Notation}

$b \quad$ width of deck cross-section

D distance

$d \quad$ height of cross-section

E Young's modulus

$\bar{M} \quad$ flexural component of restrained stress

$T_{0} \quad$ maximum gradient temperature (Priestley, 1978)

$T_{\mathrm{e}, \max } \quad$ maximum uniform bridge temperature component

$T_{\mathrm{e}, \min }$ minimum uniform bridge temperature component

$T_{\text {grad }} \quad$ New Zealand design gradient

$T_{\max } \quad$ maximum shade air temperature

$T_{\min } \quad$ minimum shade air temperature

$y \quad$ height measured upward from $1200 \mathrm{~mm}$ below the top surface (Priestley, 1978)

$z \quad$ distance of slice from the deck cross-section centroid $\alpha \quad$ coefficient of thermal expansion

$\Delta T \quad$ change in temperature

$\varepsilon \quad$ strain

$\sigma \quad$ stress

$\bar{\sigma} \quad$ axial component of restrained stress

\section{Introduction}

This paper presents the thermal data results obtained from a comprehensive, year-long monitoring programme on Waterloo
Bridge in London, UK. Specific attention is given to the thermal actions induced by variations in bridge temperature over the course of the monitoring period. The monitoring programme provides the opportunity to compare measured, real-world data with design code models, and comment on potential implications arising from any differences observed.

It is widely understood that when exposed to changes in temperature, thermal variations form within concrete bridge superstructures, which in turn induce stresses and movements. Changes in uniform bridge temperature cause longitudinal expansion and contraction, while cross-sectional temperature gradients can cause rotational deformations (e.g. Elbadry and Ghali, 1983; Hambly, 1991; Imbsen and Vandershaf, 1984; Imbsen et al., 1985; Reynolds, 1972). Emerson (1973) presents methods of calculating the temperature distribution in bridges and reports on non-linear distributions. Thepchatri et al. (1977) suggested that the forms of the temperature gradient are primarily functions of three environmental factors: ambient temperature, solar radiation and wind speed. Potgieter and Gamble (1983) developed a finite-difference programme which could accurately compute the temperature distribution through bridge superstructures based on environmental variables and material properties, such as concrete absorptivity and daily air temperature difference; they then 
complemented this with measured data from the Kishwaukee River Bridge, USA, which verified their model.

Many of these early works have contributed to the development of design guidance used today. In the UK, the Transport and Road Research Laboratory (TRRL) conducted much of the seminal work examining bridge thermal behaviour (Black et al., 1976; Emerson, 1973, 1976a, 1976b, 1977; Mortlock, 1974). The findings of these research activities are implemented in current UK bridge design specifications (BSI, 2010, 2007). Before 1989, the effects of thermal gradients on bridge structures were not accounted for in the American Association of State Highway and Transportation Officials (Aashto) specification. After a paper by Imbsen and Vandershaf (1984) recommended for their inclusion, the report Thermal Effects in Concrete Bridge Superstructures (Imbsen et al., 1985) was produced. This report built on the aforementioned work by Potgieter and Gamble (1983) and provides the basis of the specifications for thermal effects present in current Aashto specification (Aashto, 2012). Imbsen and Vandershaf (1984) presented an earlier comparison of codified approaches for thermal effects.

The continuing advancement of structural health monitoring (SHM) technology has made it easier to deploy monitoring systems on bridge structures. As a result, monitoring activities investigating thermal behaviour have been undertaken; the majority of these fall under the SHM deployment category of 'model validation' (Webb et al., 2015). A large number of these monitoring investigations are conducted on concrete bridge structures (Barsotti and Froli, 2000; Hedegaard et al., 2013; Krkoška and Moravčík, 2015; Lee, 2012; Peiretti et al., 2014; Roberts-Wollman et al., 2002). Although studies involving other bridge types have also occurred, such as steel (Kim et al., 2015; Lucas et al., 2003, 2005; Shoukry et al., 2009), fibre-reinforced polymer (FRP) (Aboelseoud and Myers, 2018; Kong et al., 2013) and integral bridges (Kim and Laman, 2010; Skorpen et al., 2018, 2019).

In this paper, Waterloo Bridge is considered to have a concretebox superstructure when calculating design thermal gradients. Notable papers have been published that relate to this bridge type. In the TRRL report entitled The Instrumentation of Bridges for the Measurement of Temperature and Movement, Mortlock (1974) described the instrumentation of seven bridges in the UK over a period of 9 years. Four of these bridges are composed of concrete superstructures. The report provided detailed descriptions of the instrumentation set-up for each bridge and demonstrated that bridge temperature could be reliably monitored over a significant amount of time. The data gathered from these bridges were subsequently used to help develop key methods, such as to estimate effective bridge temperature (Black et al., 1976; Emerson, 1976a, 1977). One of these bridges was the Hammersmith flyover, which has been subsequently monitored in recent years (Webb et al., 2014). In a study by Hedegaard et al. (2013), the I-35W St. Anthony Falls Bridge in the USA was monitored for over 3 years to measure thermal gradients. Design gradients from the Aashto load and resistance factor design (LRFD) and the New Zealand code were used to compare with the observed gradients. It was found that the measured thermal gradients were matched closest to the shape provided by the New Zealand code. Hedegaard et al. (2013) pointed out that, owing to the unique location, climate and structural properties for every bridge, the 'thermal response of structures can be highly variable' (Hedegaard et al., 2013: p. 900); implying that codes can be unnecessarily conservative for certain regions. While superstructure temperature was not directly measured, Astin (2017) monitored expansion joint movements of Waterloo Bridge for a period of 3 months between July and September 2010 and suggested that no significant movements due to temperature were measured at certain expansion joints. This was not the behaviour expected.

\subsection{Study aims}

The commissioned monitoring system pertinent to this study had the capability to take both temperature and displacement measurements (see Section 3). Although the movement data obtained were of interest to the wider project aims, they were not within the scope of this paper. This paper focuses on the measured temperature data and their comparison with international design code models for in-service temperature effects on bridge superstructures. As a result, valuable insight is gained into the thermal effects induced on a well-known urban bridge, and how well thermal behaviour aligns to thermal design models. It should be noted that the data presented in this paper relate to in-service temperature variations due to environmental conditions, and do not include early-age thermal behaviours due to the exothermic chemical reactions during construction. Results relating to the measured displacement data can be found in a forthcoming paper by Webb and Bennetts (2020) (see Section 2).

\section{Waterloo Bridge}

Waterloo Bridge is a concrete, two-way road and foot bridge in central London, UK (Figure 1), which carries the A301 over the River Thames. The north end passes over the Victoria Embankment, and the south end crosses the South Bank, which is adjacent to the National Theatre and Royal Festival Hall. Waterloo Bridge is a heavily used public transport link that is used by over 15 different bus routes and attracts high footfall from commuters and tourists daily. To mark its cultural significance, Historic England classified the bridge as a Grade II* Listed structure in 1981 (Historic England, 2015).

Constructed in 1942, the bridge is $434 \mathrm{~m}$ long and its superstructure is primarily composed of two reinforced concrete box girders and a concrete deck (Buckton and Cuerel, 1943). For 


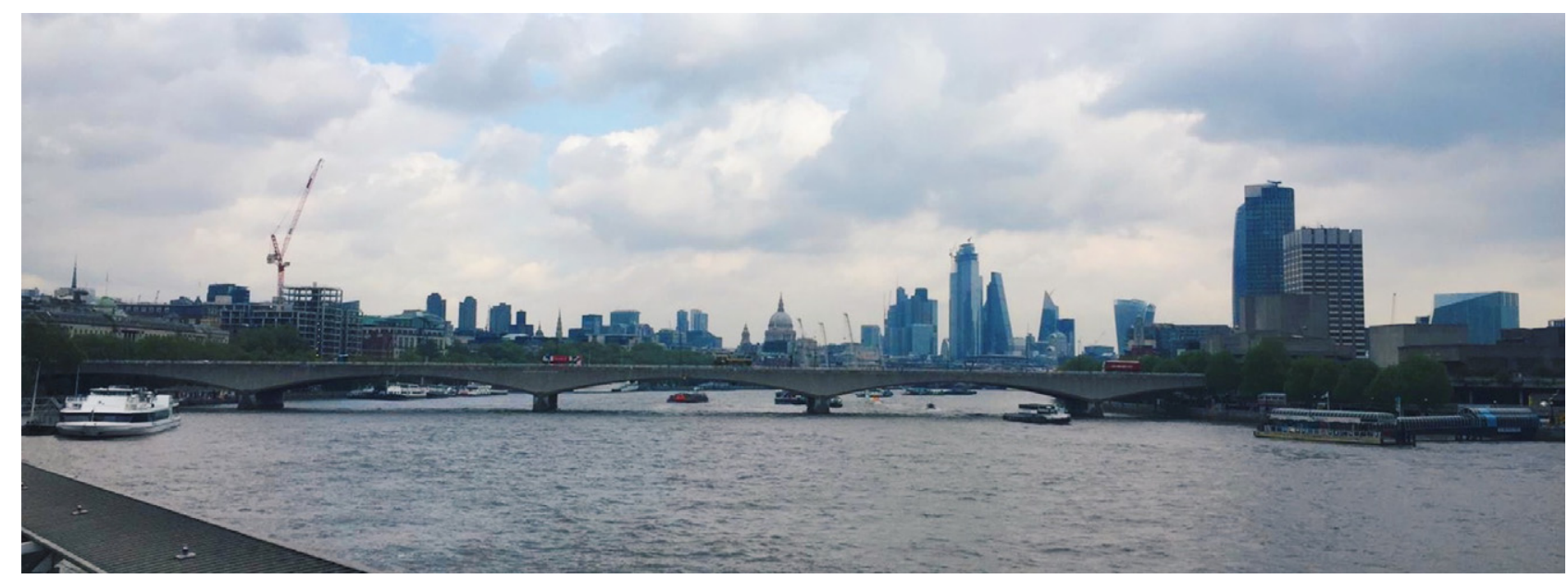

Figure 1. Waterloo Bridge facing east (photo courtesy of David Nepomuceno)

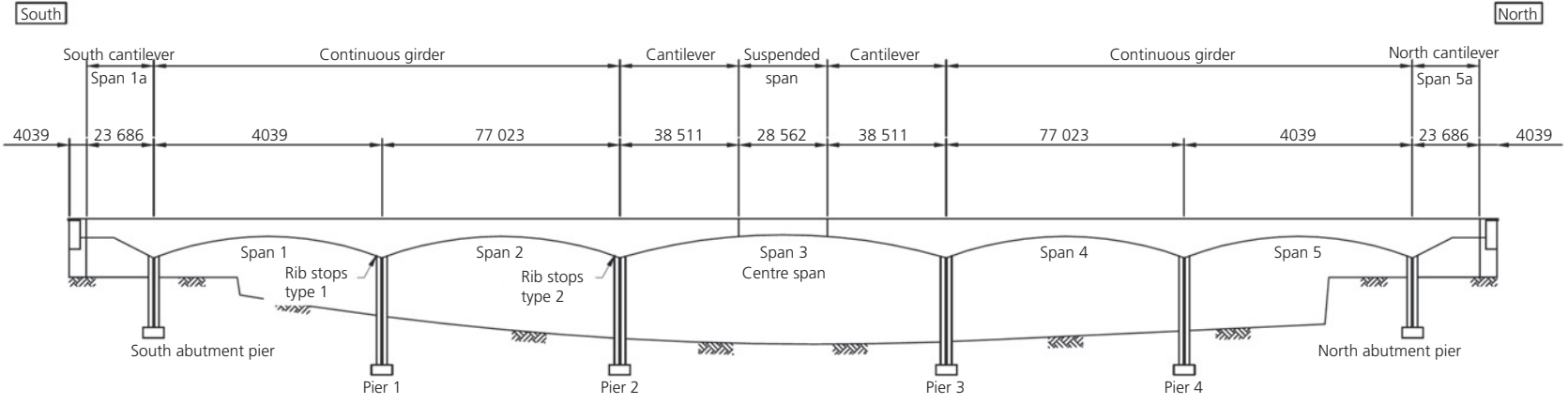

Figure 2. Elevation of Waterloo Bridge (adapted with permission from WSP (2017))

the superstructure, the concrete mix comprised cement, $50.8 \mathrm{~kg}$ $(112 \mathrm{lb})$ minimum to $63.5 \mathrm{~kg}(140 \mathrm{lb})$ maximum; and aggregates, $0.16 \mathrm{~m}^{3}\left(5(5 / 8) \mathrm{ft}^{3}\right)$. A 28 day strength requirement of $29 \mathrm{MPa}$ (4200 psi) was specified. Figure 2 shows a schematic elevation of the bridge. The structure has five primary spans and is symmetric about its mid-span. As can be seen in Figure 2, in each half of the structure, the box girders and deck are continuous over two of the spans. On the ends of each half of the structure are cantilevers, one which goes past the abutment piers and the other which projects into the middle span. The cantilevers toward the centre of the bridge support a dropin section which joins the two halves of the deck. Rib stops were fitted to the top of the vertical ribs of the pier shells which limit longitudinal deck movements. Figure 3 presents the articulation arrangement of the bridge. The bridge is allowed to expand and contract longitudinally through four expansion joints (denoted by the four horizontal black arrows in Figure 3) - one in each abutment and one at each end of the centre span. At both ends of the bridge, a cantilever supports a short approach slab which spans to the abutment. These approach slabs are supported on elastomeric bearings. Figure 3 also shows an indicative cross-section of the multi-cell box girder deck. The deck width shown stays consistent, whereas the depth varies throughout the deck. From a previous monitoring activity on the bridge, Astin (2017) states that although the bridge in its current condition can safely carry a $40 \mathrm{t}$ assessment load, the bridge had 'serious shortcomings' (Astin, 2017: p. 63) when compared with modern-day design standards.

Waterloo Bridge is part of Westminster City Council's (WCC) asset stock. Under an agreement current at the time of writing, FM Conway are the contractors for the repair, maintenance, renewal and improvement of WCC's 'highways infrastructure assets and the public realm'. Waterloo Bridge is one of the assets covered by this framework agreement. As is common practice in the UK, the bridge is subject to an inspection regime that consists of a general inspection (GI) and a principal inspection (PI). A GI - which occurs every 2 years is defined as a 'visual inspection of all parts of the structure that can be inspected without the need for special access 


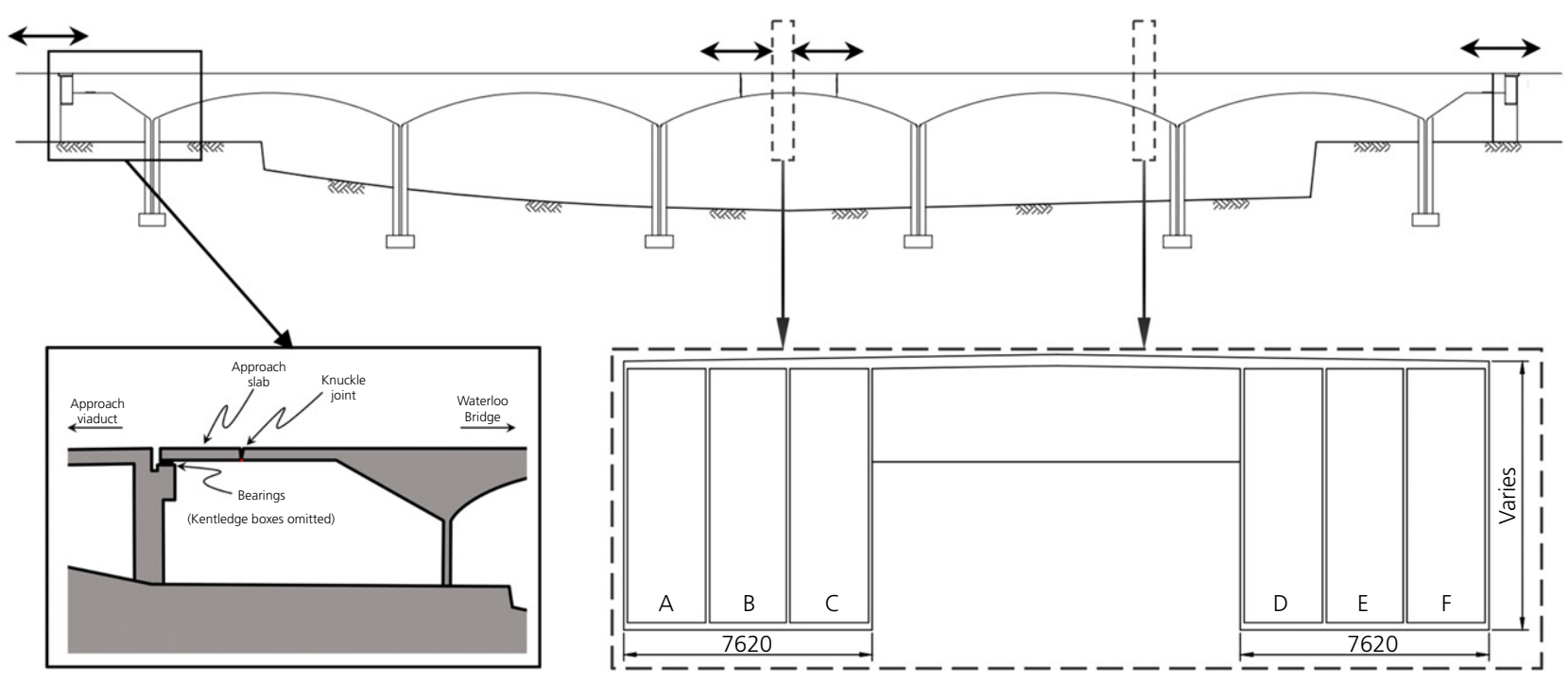

Figure 3. Articulation arrangement of Waterloo Bridge (adapted with permission from WSP (2017))

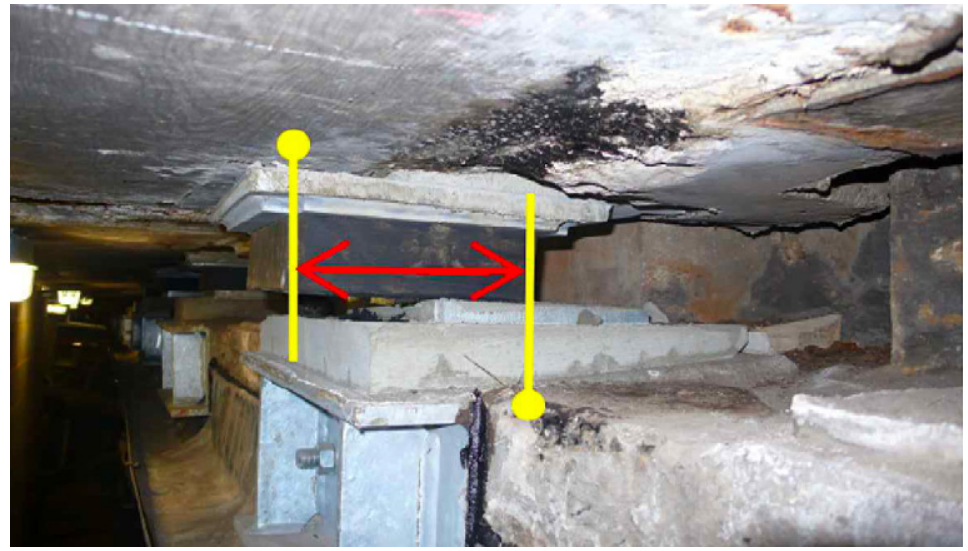

(a)

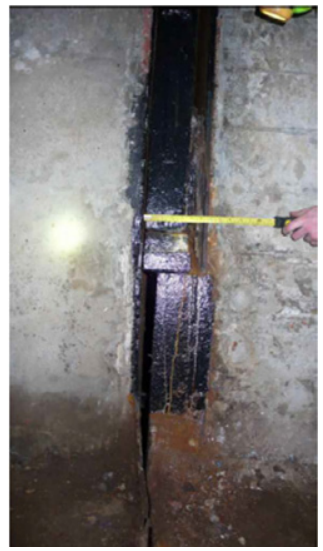

(b)

Figure 4. (a) Example of displaced abutment bearing on Waterloo Bridge; (b) typical example of the roller bearings on Waterloo Bridge (adapted with permission from WSP (2017))

equipment' (Highways England, 2017: cl. 3.5 .2 3/3). A PI occurs every 6 years, and can be defined as a 'close examination, within touching distance, of all inspectable parts of the structure' (Highways England, 2017: cl. 3.6.2 3/4). These inspections are often the primary method of stock assessment by bridge owners, but owing to their subjective nature, they can be unreliable and inaccurate (Bennetts et al., 2016, 2018; Nepomuceno et al., 2021). Current activities related to the maintenance of Waterloo Bridge have highlighted the need to undertake a comprehensive range of testing, instrumentation and monitoring of the structure to inform the assessment of its strength and durability for its residual design life.
From previous inspections of the bridge, two main concerns were highlighted. First, the main roller bearings across the drop-in span's joints showed signs of deterioration and silt build-up, potentially constricting thermal expansion and contraction. This could introduce additional stresses within the structure and affect how thermal expansion is accommodated. Second, some of the bearings supporting the approach slabs (shown in Figure 4) had failed and had been displaced from their supports. As a result of these potential issues, a monitoring programme was therefore commissioned by WCC to gain an understanding of the current thermal behaviour and articulation of the bridge, whereby the collected data would allow existing structural 
models to be refined and help inform the design of any remedial works.

The work in this paper studies the temperature data obtained from the monitoring programme, comparing the observed inservice thermal behaviour with pertinent design code models. Findings related to the bridge's articulation are discussed in a forthcoming paper by Webb and Bennetts (2020) and also in Selvakumaran et al. (2019). Regarding the aforementioned concern of the central drop-in span movement joints being restricted, Webb and Bennetts (2020: p. 7) found 'no evidence to suggest that there is significant frictional restraint to movement' from the displacement data. Using the findings, they take an empirical approach to derive a design movement range for the south abutment bearing replacements. Selvakumaran et al. (2019) investigate the potential efficacy of satellite measurement technologies in bridge monitoring. In addition to the commissioned monitoring programme, two automated total stations (ATS) were set up to track reflective prisms attached to the sides of the bridge. These ATS data were then compared with interferometric synthetic aperture radar (InSAR) satellite measurements. While the ATS and InSAR measurements were found to be comparable, Selvakumaran et al. (2019: p. 647) conclude that, at present, satellite monitoring is 'not a technique that could replace traditional monitoring methods'; however, they do note its potential value in supplementing traditional inspection programmes.

\section{The installed monitoring system}

A remote monitoring system was installed on the bridge by Mistras Group Ltd (Cambridge, UK), consisting of 48 temperature sensors and 20 displacement transducers. Collectively, these 68 sensors were referred to as the structural monitoring system (SMS). The SMS was commissioned on 12 December 2017, after which the bridge stayed open for normal use with no significant maintenance activities carried out over the monitoring period. The technical specification for the SMS is detailed in WSP (2017).

The work in this paper specifically focuses on the thermal data collected by the SMS temperature sensors. The temperature sensors were installed at four cross-sections throughout the bridge length (see Figure 5) so that a range of deck depths could be monitored. The four cross-sections were located as follows:

- in the central drop-in span ('span 3' in Figure 5), where deck depth is at a minimum (hereby referred to as the 'span section')

- near pier 4, where deck depth is near to maximum (hereby referred to as the 'pier section')

- in the north abutment approach slab

- in the south abutment approach slab.

The indicative positions of the sensors at each cross-section are shown inset in Figure 5, with the exact deck depths for the

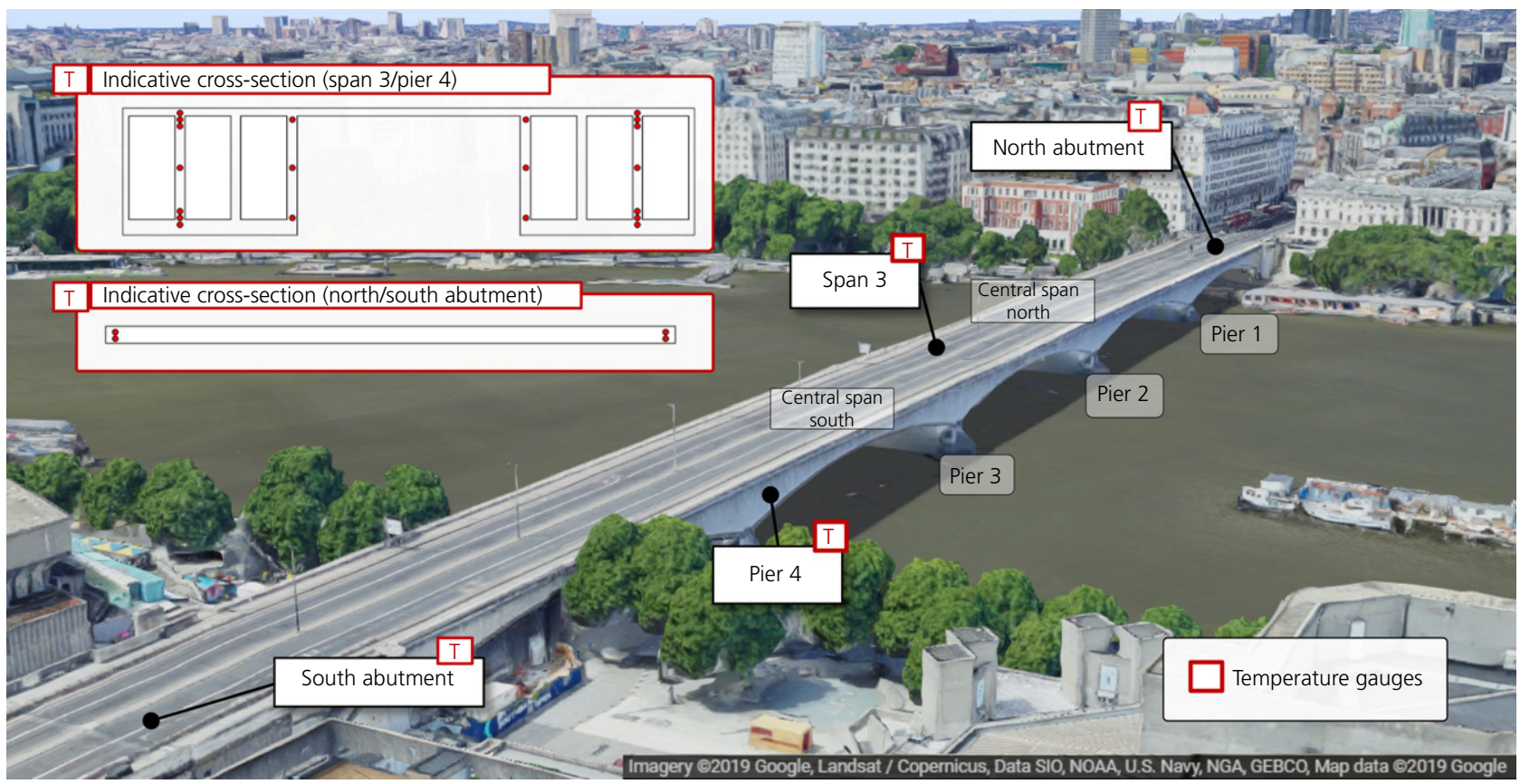

Figure 5. Representative sensor locations on Waterloo Bridge (@ Google 2019) 


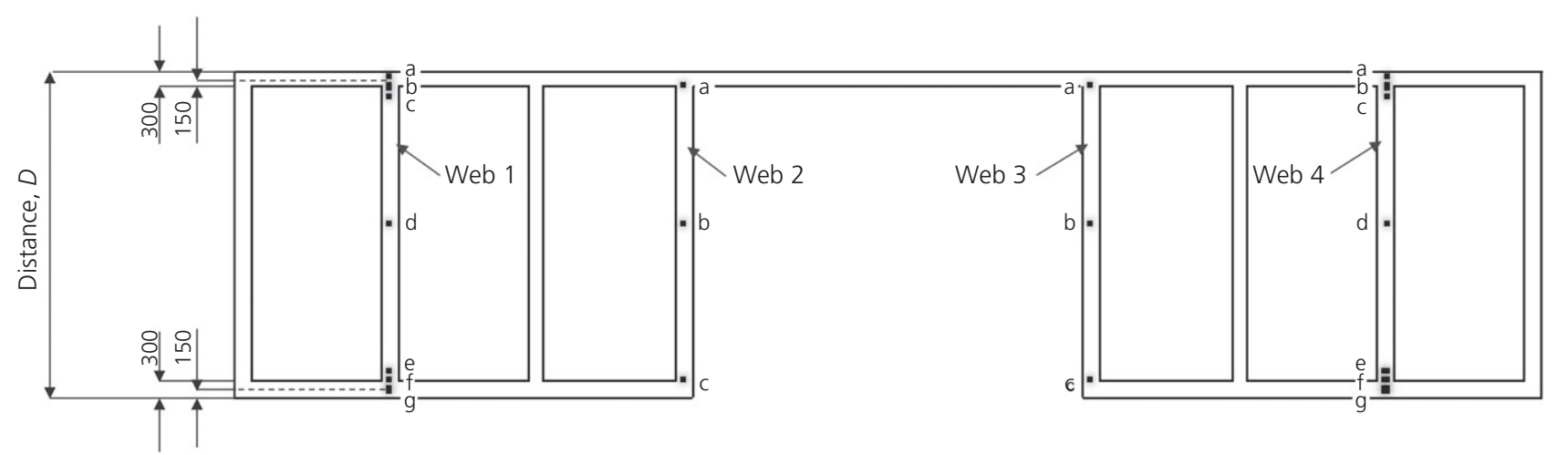

Figure 6. Temperature sensor deck depths at span and pier sections (see Table 1 for measurements)

Table 1. Temperature sensor depths at span and pier sections (see Figure 6)

\begin{tabular}{lll} 
Web & Sensors & Distance from section top \\
\hline 1 & a & $150 \mathrm{~mm}$ \\
& b & $300 \mathrm{~mm}$ \\
& c & $450 \mathrm{~mm}$ \\
d & $0.5 D$ \\
& e & $D-450 \mathrm{~mm}$ \\
& f & $D-300 \mathrm{~mm}$ \\
& g & $D-150 \mathrm{~mm}$ \\
& a & $300 \mathrm{~mm}$ \\
& b & $0.5 D$ \\
& c & $D-300 \mathrm{~mm}$ \\
& a & $300 \mathrm{~mm}$ \\
& b & $0.5 D$ \\
& c & $D-300 \mathrm{~mm}$ \\
& a & $150 \mathrm{~mm}$ \\
& b & $300 \mathrm{~mm}$ \\
& c & $450 \mathrm{~mm}$ \\
& d & $0.5 D$ \\
& e & $D-450 \mathrm{~mm}$ \\
& f & $D-300 \mathrm{~mm}$ \\
& g & $D-150 \mathrm{~mm}$
\end{tabular}

span and pier sections depicted in Figure 6 and Table 1. This layout was chosen so that transverse and vertical temperature distributions could be monitored. The variation of temperature was expected to be largest near the top and bottom surfaces of the bridge and so the installed sensors were concentrated in these areas. Due to solar radiation, it was anticipated that the outer webs were likely to be subject to much higher heat transfer than the inner webs, and so the sensors were placed away from the outermost web so that this did not distort temperature measurements. The temperature gauges were embedded within the concrete, and a suitable grout was used to fill the resulting cavities such that the internal temperature of the concrete was accurately measured. A photograph of some of the

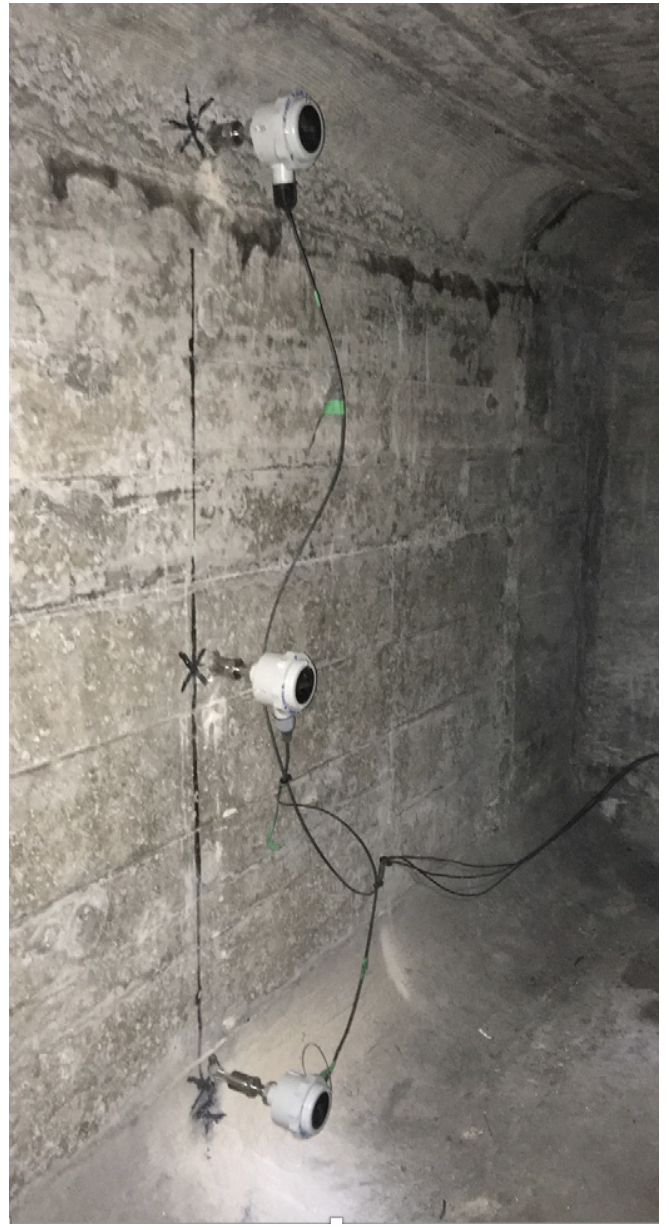

Figure 7. Photograph of installed temperature sensors (photo: WSP)

installed thermocouples can be seen in Figure 7. Details of the model style 2 temperature sensor from Status Instruments (Tewkesbury, UK) can be found in Table 2. 


\begin{tabular}{lllll} 
Brand/Model & Standard & Material & Measurement range: ${ }^{\circ} \mathrm{C}$ & Accuracy: ${ }^{\circ} \mathrm{C}$ \\
\hline Status Instruments Style 2 & PT100 to BS SN 60751 IEC751 Class B & 316 stainless steel & -50 to 200 & \pm 0.02
\end{tabular}

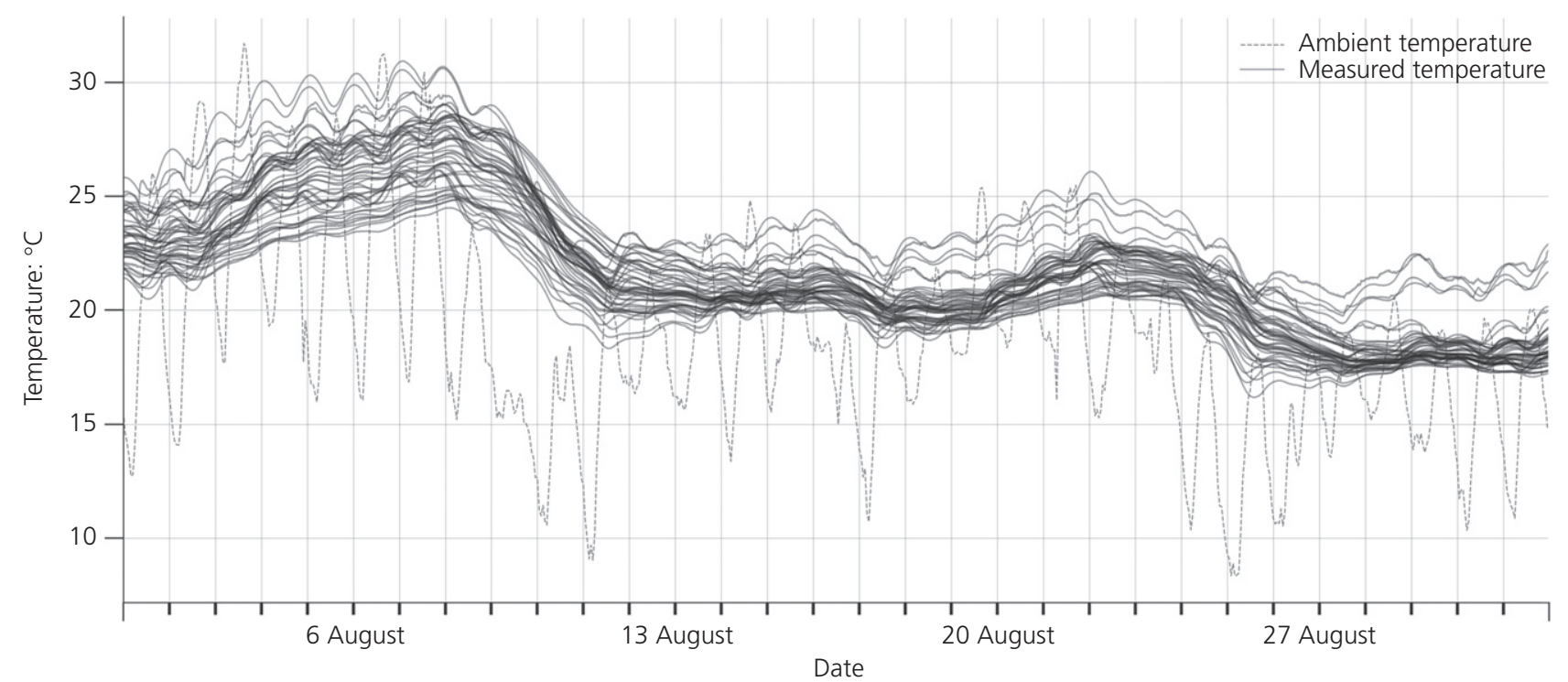

Figure 8. Sample of the measured temperature data from all four monitored cross-sections and the ambient temperature data in August 2018

The SMS system was programmed to take temperature and displacement readings at a rate of five per second. After 10 January 2018, this rate was changed to one per second to meet the sampling frequencies in the technical specification. Although monitoring was initially scheduled to go over the course of a full year, technical issues concerning the system contractor meant that data were collected up to 30 November 2018. The raw data were processed to produce a smaller dataset that averaged the readings from each channel to $5 \mathrm{~min}$ intervals, thereby reducing the effect of random measurement errors. This more manageable dataset was used for all the data interpretation activities undertaken in this paper.

\section{Visualising measured thermal data}

Using the collected data, plots were produced that would aid in understanding the thermal behaviour of the bridge. To enable this, daily ambient temperature data were also considered, alongside temperature measurements taken from the gauges installed on the bridge. A sample of the temperature data from the $5 \mathrm{~min}$ dataset for August 2018 is plotted in Figure 8, along with hourly ambient temperature data. This plot includes data from each temperature sensor at each of the four monitored cross-sections.

\subsection{Ambient temperature}

The Dark Sky API was used to obtain hourly ambient temperatures over the course of the monitoring period. Dark Sky

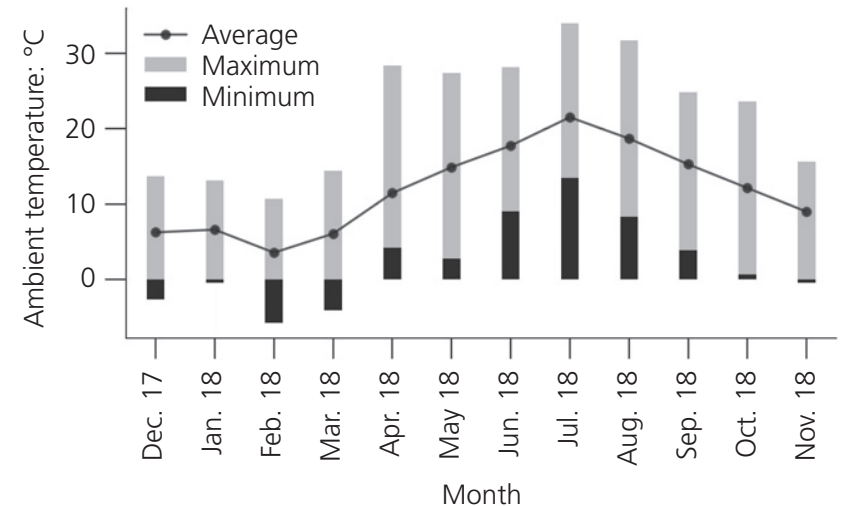

Figure 9. Summary of the monthly ambient temperatures (minimum, maximum and average) during the monitoring period

uses a variety of international weather station sources and modelling techniques to provide accurate weather data for a specific location (Dark Sky, 2020). Figure 9 shows the monthly maximum, minimum and average ambient temperatures taken from this dataset. The year 2018 was notable for its drastic seasonal temperatures in the UK. In particular, severe winter weather was experienced in late February and March (Press Office, 2018a), while the summer was declared the joint hottest 
summer on record (Press Office, 2018b). Nearby the bridge, the maximum temperature reached was $34.0^{\circ} \mathrm{C}$ in July 2018, while a minimum of $-5.8^{\circ} \mathrm{C}$ occurred in February 2018, giving a total temperature range of $39.8^{\circ} \mathrm{C}$. The average ambient temperatures over the summer and winter months were $19.3^{\circ} \mathrm{C}$ and $5.8^{\circ} \mathrm{C}$, respectively.

\subsection{Measured uniform bridge temperature component}

Figure 10 shows the measured bridge temperature at each of the monitored cross-sections (span 3, pier 4, north and south abutments) over the monitoring period. These were derived by calculating the average of the temperature measurements from each sensor at the corresponding cross-section, weighted by the estimated area of the cross-section that each sensor covers. In general, both daily and seasonal variations can be seen in the data. The temperatures in the span section and pier section are similar, though the span appears to show a larger variation range in its readings. This could be due to the smaller thermal mass of the section, given its thinner cross-section. The approach slabs in the north and south abutments exhibit higher temperatures compared to the deck. The data appear to show that these temperatures are affected by a nightclub and a plant room for the BFI Southbank building, which are located underneath the north and south abutments, respectively. It is possible that these identified areas were generating heat and causing this increased temperature in the approach slabs. Regarding the deck sections, the minimum temperature and maximum temperature both occur in the span section, reaching a low of $-0.6^{\circ} \mathrm{C}$ and a high of $27.5^{\circ} \mathrm{C}$.

\section{Design model comparisons}

BS EN 1991-1-5 (BSI, 2010) and the UK National Annex (BSI, 2007) provide a thermal loading model, which was used to compare with measured temperature ranges and distributions. The temperature distribution of the bridge can be regarded as the sum of two components: $(a)$ a uniform temperature component - which determines the expansion and contraction of the bridge longitudinally, and (b) a temperature difference component - these can vary along the depth and width of the bridge, leading to bending and twisting effects, as well as internal stresses. These design models are considered in Sections 5.1 and 5.2. For the remainder of the paper, BS EN 1991-1-5 and the UK National Annex are referred to as the 'UK design model'.

\subsection{Uniform bridge temperature component}

In the UK design model, the design range of uniform bridge temperature is calculated from the expected ambient temperature range for a bridge's location (BSI, 2010, 2007). This expected ambient temperature range is derived from isotherms of shade air temperatures in the UK National Annex, and the correlation between the minimum $\left(T_{\min }\right)$ and maximum $\left(T_{\max }\right)$ shade air temperatures and the minimum $\left(T_{\mathrm{e},}\right.$ min $)$ and maximum $\left(T_{\mathrm{e}, \max }\right)$ uniform bridge temperatures is estimated by (BSI, 2010: cl. 6.1.3.1):

\section{1. $T_{\mathrm{e}, \min }=T_{\min }+2$}

\section{2. $T_{\mathrm{e}, \max }=T_{\max }+8$}

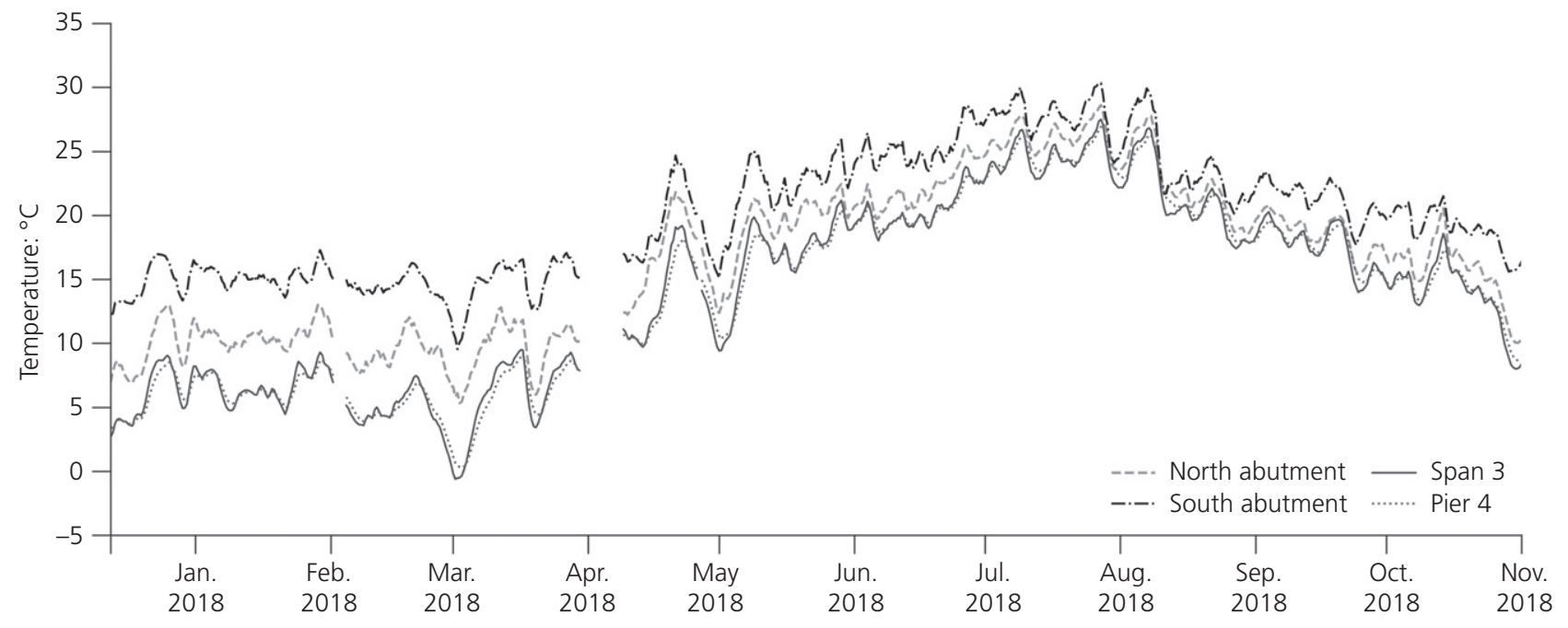

Figure 10. Variation in uniform temperature component estimated from measured data at each cross-section over the course of the monitoring period 
The resulting parameters used in the calculation of design limits are outlined in Table 3.

A plot of the average deck temperature (which is the mean of the span and pier readings from Figure 10) and the measured daily minimum and maximum ambient temperatures is presented in Figure 11. Overlaid are the corresponding minimum and maximum design limits (i.e. $T_{\min }, T_{\max }, T_{\mathrm{e}}$, min and $T_{\mathrm{e}, \text { max }}$ ). A clear relationship can be seen between the measured uniform bridge temperature and the ambient temperature over the course of the monitoring period. Owing to the structure's thermal mass, a damped response in the bridge temperature was observed. It is also seen that the uniform bridge temperature stayed within the calculated design limits.

The design relationships represented in Equations 1 and 2 are plotted as solid lines in Figure 12. As the line derived from Equation 1 is intended to be used for determining the minimum uniform bridge temperature, it has been plotted for ambient temperatures below $0^{\circ} \mathrm{C}$. Conversely, the (lighter) line derived from Equation 2 has been plotted for ambient temperatures above $30^{\circ} \mathrm{C}$ as it is used to determine the maximum uniform bridge temperature. The measured deck temperatures are then plotted against the corresponding daily minimum and maximum ambient air temperatures, which are represented by dots and triangles, respectively.

These design relationships provided by the UK model are expected to be more extreme than measured values from the structure, as they are expected to account for the most extreme conditions likely to be experienced over the lifetime of a bridge. In the context of Figure 12, the maximum measured deck temperatures (triangles) at high temperatures would be expected to lie below Equation 2, whereas the minimum measured deck temperatures (dots) at low temperatures would be expected to be above Equation 1. This behaviour was observed for the maximum deck temperatures, but not for the minimum deck temperatures, where most of the measurements are below the darker shaded line. This suggests that the minimum bridge deck temperature may be lower than what the design thermal model in the UK standard predicts. This may be potential justification for proposing an alternative thermal model, which can be used in any future remedial solutions,

Table 3. Parameters used in design limits according to BS EN 1991-1-5

\begin{tabular}{|c|c|c|c|}
\hline Parameter & Symbol & Value & Comments \\
\hline Bridge deck type & - & Type 3 & Concrete deck: box girder \\
\hline Minimum shade air temperature & $T_{\min }$ & $-10^{\circ} \mathrm{C}$ & Derived from isotherms in UK NA \\
\hline Maximum shade air temperature & $T_{\max }$ & $35^{\circ} \mathrm{C}$ & Derived from isotherms in UK NA \\
\hline Minimum uniform bridge temperature component & $T_{\mathrm{e}, \min }$ & $-2^{\circ} \mathrm{C}$ & Calculated from Equation 1 \\
\hline Maximum uniform bridge temperature component & $T_{\mathrm{e}, \max }$ & $37^{\circ} \mathrm{C}$ & Calculated from Equation 2 \\
\hline
\end{tabular}

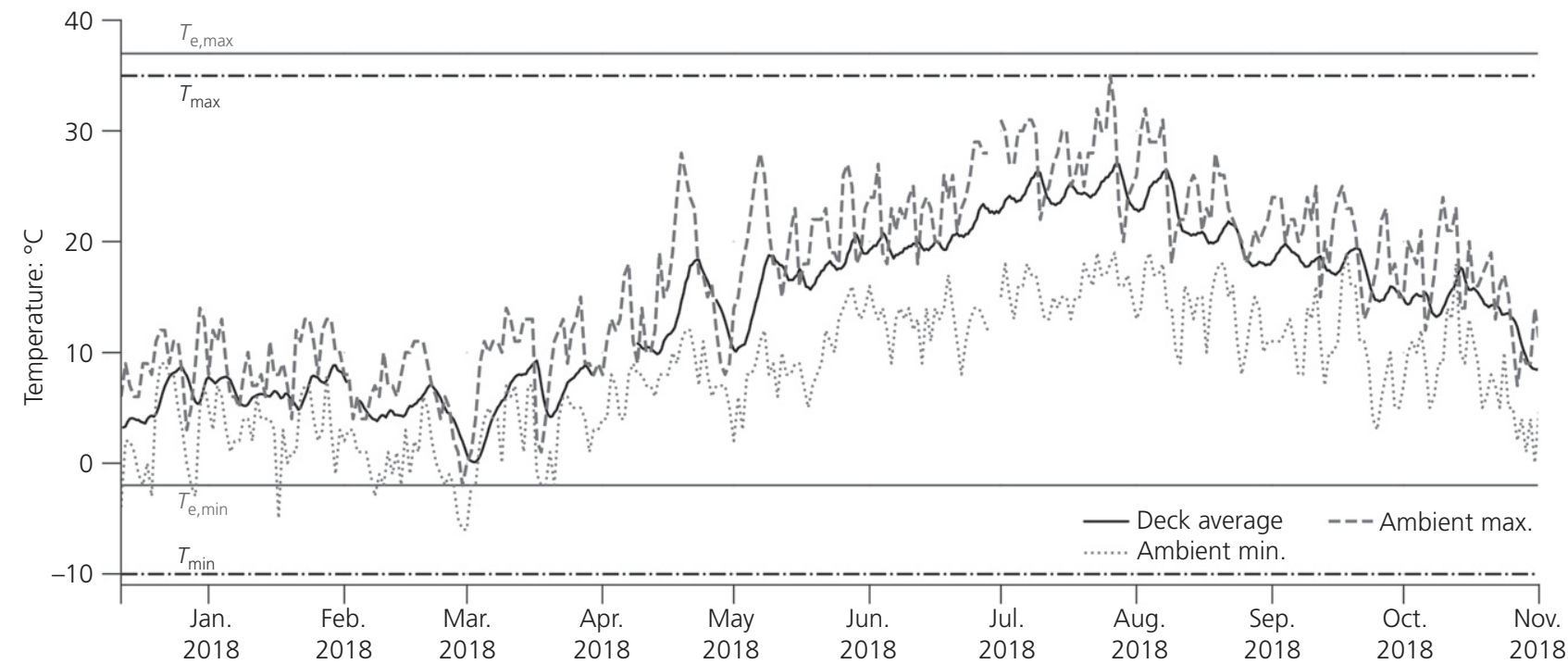

Figure 11. Variation in measured bridge temperature and ambient temperature 


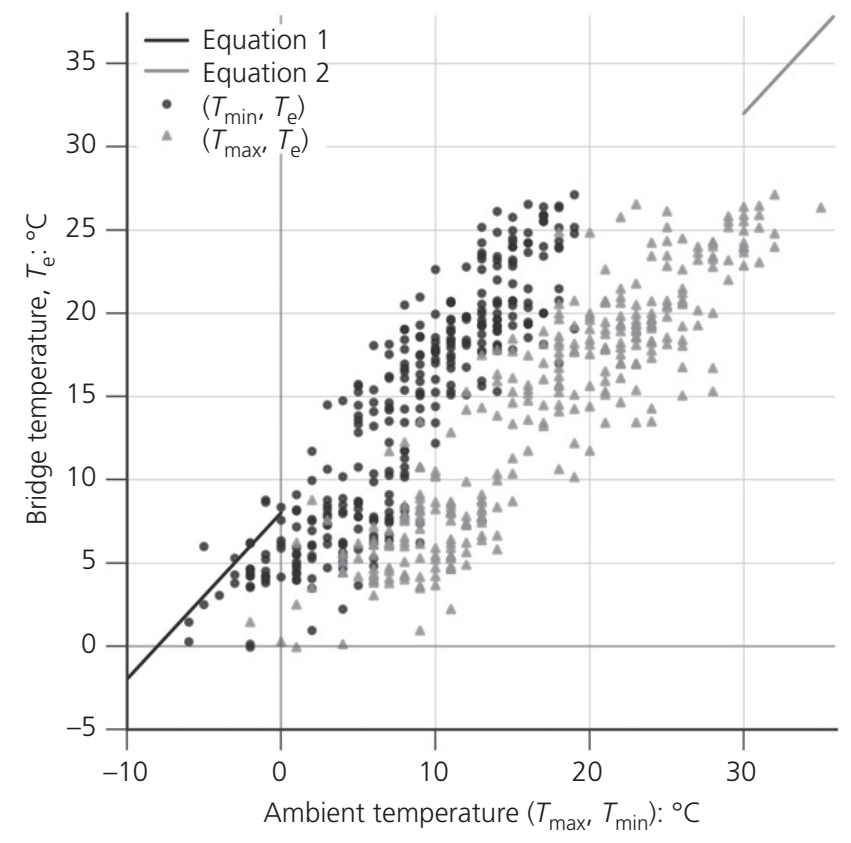

Figure 12. Relationship between uniform bridge temperature and ambient temperature

and which could involve reducing both the maximum and minimum uniform bridge components.

\subsection{Vertical temperature difference component}

A vertical temperature variation that occurs through a bridge's cross-section can induce bending effects in a structure. This is especially of interest with Waterloo Bridge, owing to its unusual articulation arrangement and large variation in crosssection depth. These vertical temperature differences are primarily due to the top surface gaining heat through solar radiation, causing heat to flow down through the structure. A positive temperature difference can be defined as the surface of the deck being higher in temperature than the webs, whereas a negative temperature difference is when the surface temperature is lower than that of the webs. The UK design code provides curves of vertical temperature difference for periods of 'heating' and 'cooling', which can be used to model these positive and negative temperature differences, respectively (BSI, 2010: cl. 6.1.4.2). 'Heating' refers to when heat is gained through the top surface of the bridge deck, while 'cooling' refers to when heat is lost through the top surface.

The design gradients provided by Aashto LRFD bridge design specifications (Aashto, 2012) and the New Zealand bridge manual (SP/M/022) (NZTA, 2016) were also considered in this part of the study. These will now be referred to as the US and NZ design model, respectively. A summary of the three design gradients as applied to the span cross-section can be found in Table 4. For the US gradient, the positive temperature difference values used correspond to solar radiation zone 2 (Aashto, 2012), and the negative temperature difference values were calculated by multiplying the positive values by -0.3 (as stipulated). The design gradient from the NZ code is notable for its fifth-order curve developed by Priestley (1978), which decreases from a maximum temperature difference, $T_{0}$, at the surface, down to zero at a depth of $1200 \mathrm{~mm}$. The equation that defines this curve is

$$
\text { 3. } T(y)=T_{0}\left(\frac{y}{1200}\right)^{5}
$$

where $y$ is the height measured up from $1200 \mathrm{~mm}$ below the top surface. The NZ code requires use of the negative temperature values from the Australian code AS5100.2-2004 (SA, 2017); which consists of a stipulated negative temperature variation at the top surface that increases linearly to zero at a depth of $300 \mathrm{~mm}$.

An illustration of the three design codes superimposed on the span section is shown in Figure 13. Observations show that at the top surface, the NZ code provides both the highest and lowest limits for the positive and negative temperature differences, respectively. It is also notable how the UK 'heating' and 'cooling' limits are less extreme than both the US and NZ top surface temperature differences. For the bottom surface, the variation in the positive temperature differences limits between the three codes is much less pronounced, with the US having the highest limit. The UK 'heating' limit covers the least height, while the 'cooling' (i.e. negative) limit covers the most height. This 'cooling' limit for the bottom surface is greater than the US negative limit. The NZ code does not specify a negative component for the bottom surface. These design curves are calibrated so that their effects (i.e. imposed stresses/strains) are representative of the worst-case effects expected for a given cross-section type. They are not necessarily intended to predict the temperature for any depth in the cross-section accurately.

The plots in Figures 14-16 illustrate the vertical temperature differences for the span and pier sections at a given timestamp; accompanied by a plot showing the variation in measured bridge temperature (with a one day period either side of the timestamp). This is to help indicate the movement of the general deck temperature temporally. Measurements taken from sensors on the west side of the bridge are plotted as dots, with the eastern sensors plotted as crosses. Through these plots it is possible to observe the thermal behaviour of the deck, in terms of which surface heat was being gained and lost through. The design curves are also plotted to indicate whether the measured temperature difference values differ significantly from the design curves, potentially implying onerous stress/strain effects. 
Table 4. Summary of design thermal gradients as applied to the span section

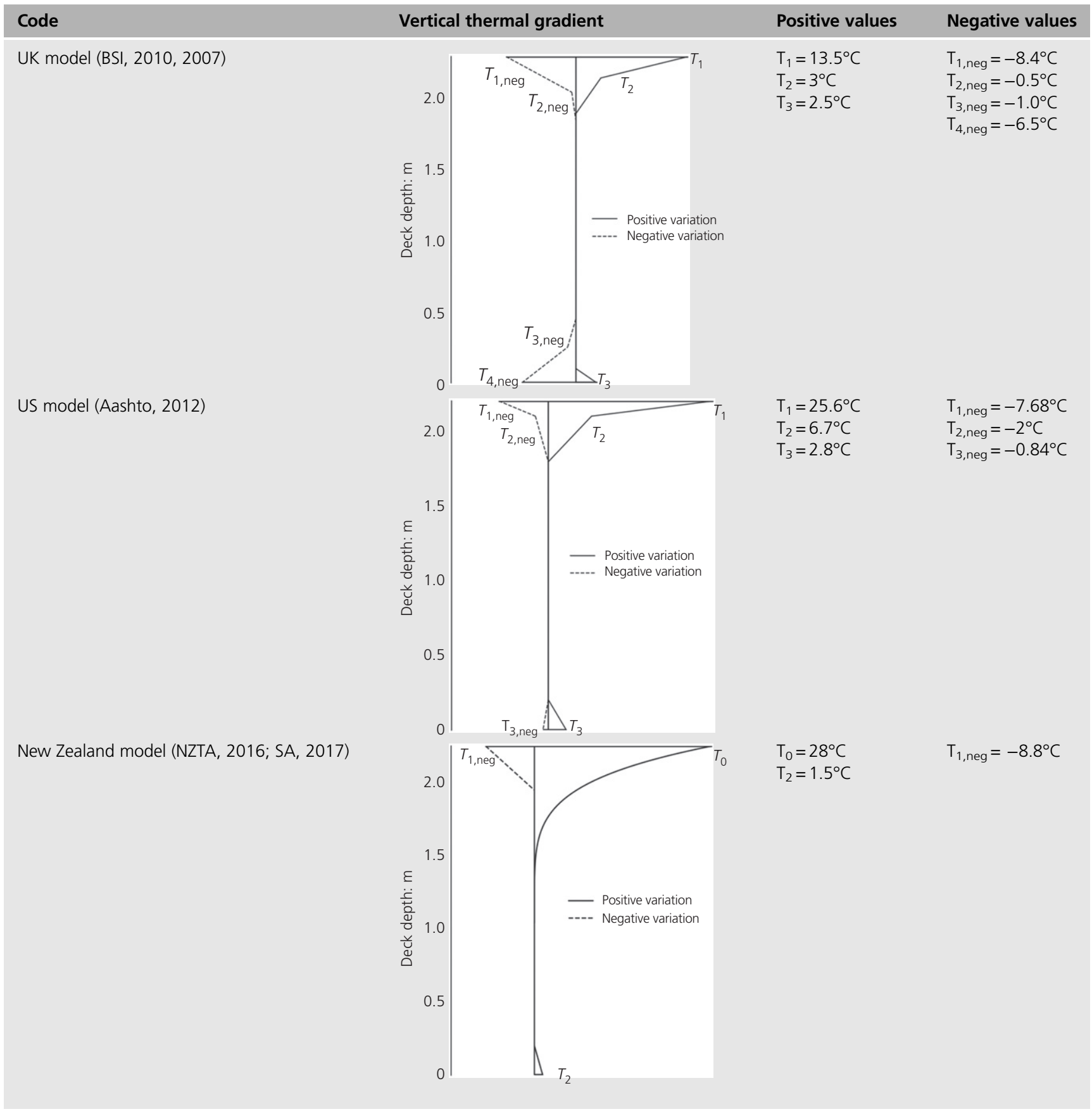

The plot in Figure 14 indicates a period in May, where the overall deck temperature was increasing. The span section appears to be gaining heat through both the top and bottom surfaces, while the pier section gains heat through the top surface and loses heat through the bottom surface. It is noted that there was an anomalous west sensor at the top surface of the pier section, which measured a negative variation. This may be due to a fault with this specific sensor, as this seemingly anomalous variation was observed in other plots. The plot in Figure 15 indicates a colder period in March where the overall deck temperature was increasing. In the span section, it can be observed that heat was being lost through the top surface and heat gained through the bottom surface. The pier section also gains heat through the bottom surface, but exhibits smaller temperature variations. The plot in Figure 16 indicates a warmer period in June, where the overall deck 


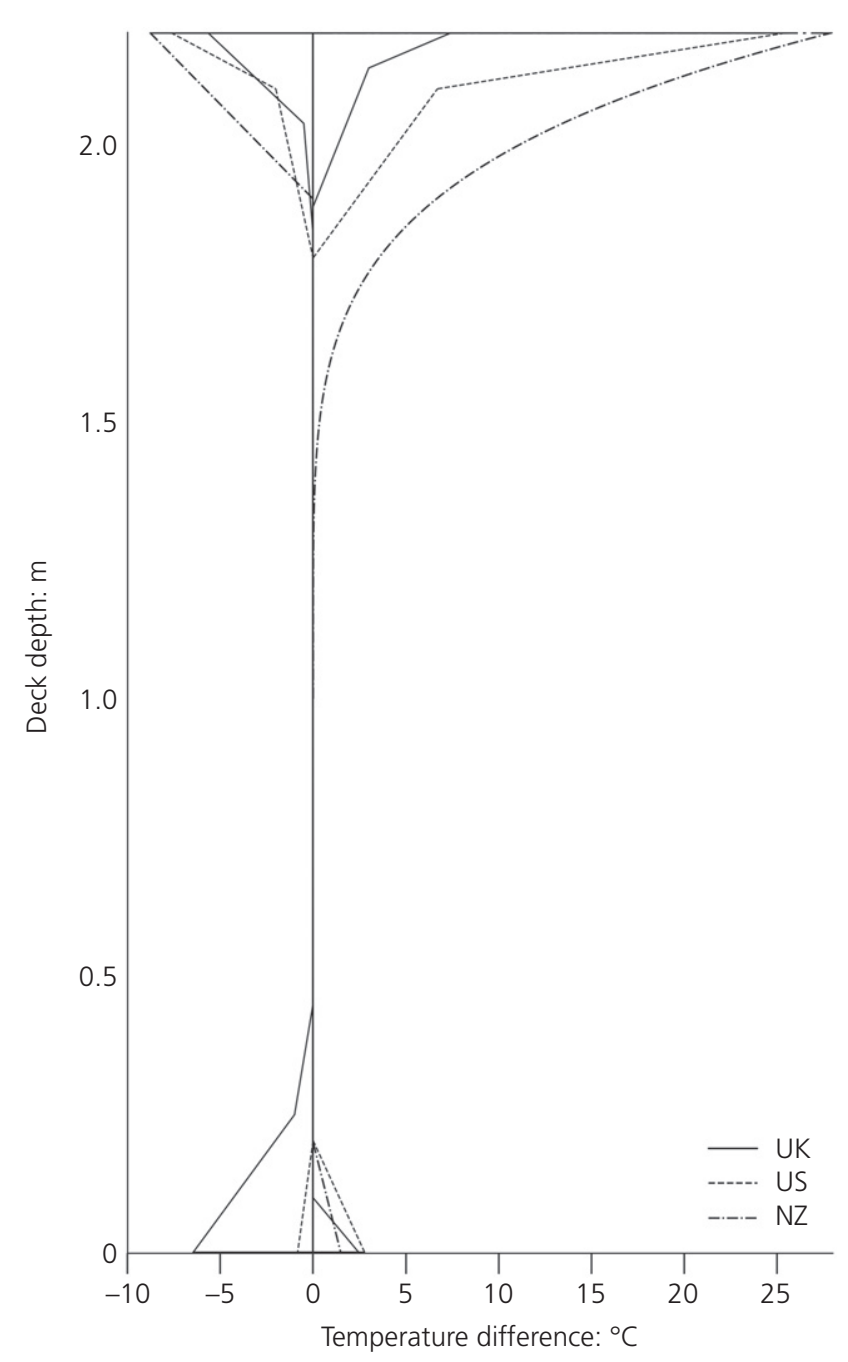

Figure 13. Combined design thermal gradients as applied to the span section

temperature was decreasing. The span and pier sections appear to exhibit the same thermal behaviour of gaining heat through the top surface and losing heat through the bottom surface. In general, it was observed that several of the measured temperature difference values exceed the design curves, suggesting that the imposed effects may be more onerous than the effects that would be expected from the design curves. This is further explored in Section 6, where the imposed forces resulting from these vertical temperature variations are investigated.

\section{Estimated deck effects from vertical temperature differences}

Using the vertical temperature difference values analysed in the previous section, the structural effects imposed on the bridge deck can be estimated. This allows for meaningful comparisons to be made between the measured values and the design curves. The analysis procedure used in this section follows closely to that found in Bridge Deck Behaviour (Hambly, 1991). If an element is unrestrained, a rise in temperature will cause it to expand. If instead, the element is restrained, an increase in temperature induces an increase in stress because the element is fixed and cannot deform. The uneven distribution of stress resulting from a non-uniform temperature distribution can be taken as the starting point for calculating the effects of temperature loading in the deck structure. By assuming that the deck is rigidly restrained throughout, it is possible to calculate the stresses in the restrained slice and then 'remove' the theoretical restraints, to estimate the resultant stresses.

The first plot in Figure 17 shows the non-linear 'heating' curve stipulated in the UK design model for the span section. The unrestrained thermal strains are given by

\section{4. $\varepsilon=\alpha \Delta T$}

where $\varepsilon$ is the strain; $\alpha$ is the coefficient of thermal expansion $\left(12 \times 10^{-6}{ }^{\circ} \mathrm{C}^{-1}\right)$; and $\Delta T$ is the change in temperature. This would result in the strains shown in the second plot in Figure 17 if all horizontal slices of the deck are assumed to be unrestrained. When expansion of the section is hindered, then the locked-in stresses are

\section{5. $\sigma=\alpha E \Delta T$}

where $E$ is the Young's modulus. For an $E$ value of $30 \mathrm{GPa}$, this causes the stresses found in the third plot of Figure 17 for a rigidly restrained section.

The effects of applying a non-uniform temperature change to a structure are highly dependent on the configuration of the structure and its boundary conditions. If a temperature difference is applied to a beam that is fully fixed at both ends then no movement or rotation will occur at the ends, but an axial force and a moment will be generated. If instead the ends of the beam are completely free then there will be no resultant axial force or moment, but there will be a change in axial length and curvature. In order to compare the effects of different temperature distributions in this paper, the moments that would be induced in a fully restrained section will be considered. With this in mind, the stress distribution in the third plot of Figure 17 can be considered as being composed of three components: an axial component, a bending component and a self-equilibrating internal component. Figure 18 illustrates this for the span section. To account for this, an additional axial force must be superimposed on this fully fixed section of the deck. Imagining that the axial restraint is 

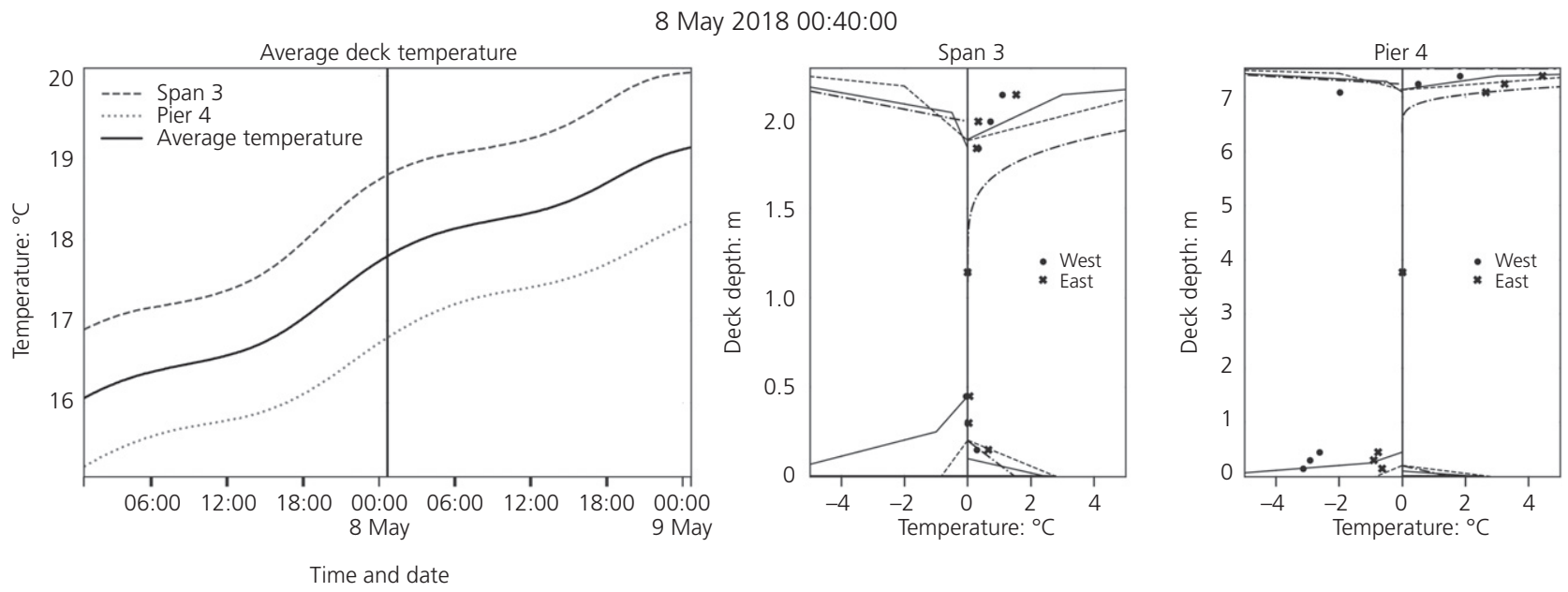

Figure 14. Plot showing vertical temperature difference in a period in May 2018

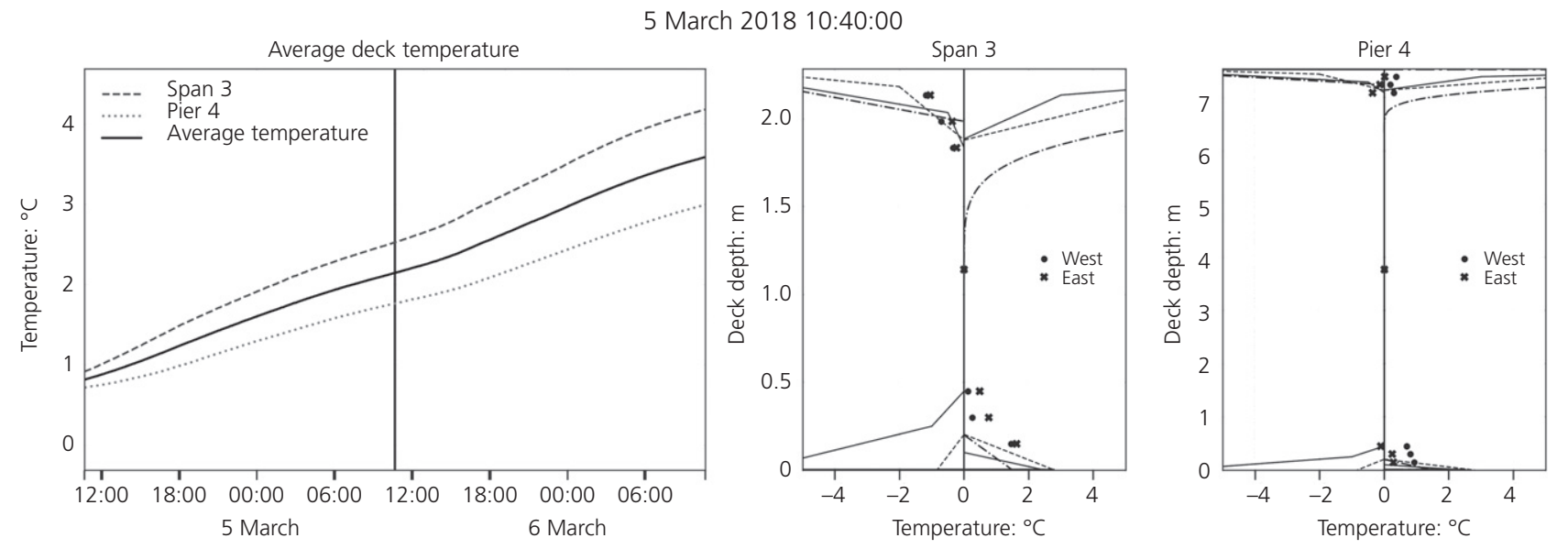

Figure 15. Plot showing vertical temperature difference in a period in March 2018

removed, an axial force is superimposed. This is equal to the integral of the stress with respect to the cross-sectional area of the section, which is denoted by

6. $\quad \bar{\sigma}=\int_{0}^{d} \frac{\sigma b d z}{\text { area }}$

where $b$ is the width of the cross-section. The deck is primarily composed of two concrete box girders. For this analysis, half of the span's cross-sectional area was considered (i.e. one concrete box girder). This results in the axial component value of $717566 \mathrm{Nm}^{-2}$ (see the second plot in Figure 18). The moment restraint can also be imagined as being removed, which is the same as applying a moment about the centroid of the section. This is equal to integrating the stress multiplied by the lever arm over the cross-sectional area. This is denoted by

7. $\bar{M}=\int_{0}^{d} \sigma b z d z$

where $z$ is the distance from the centroid. This results in the flexural component denoted in the third plot of Figure 18, which varies linearly from $792533 \mathrm{Nm}^{-2}$ at the top surface, down to $-792533 \mathrm{Nm}^{-2}$ at the bottom surface. Subtracting both the axial and flexural component from the restrained 

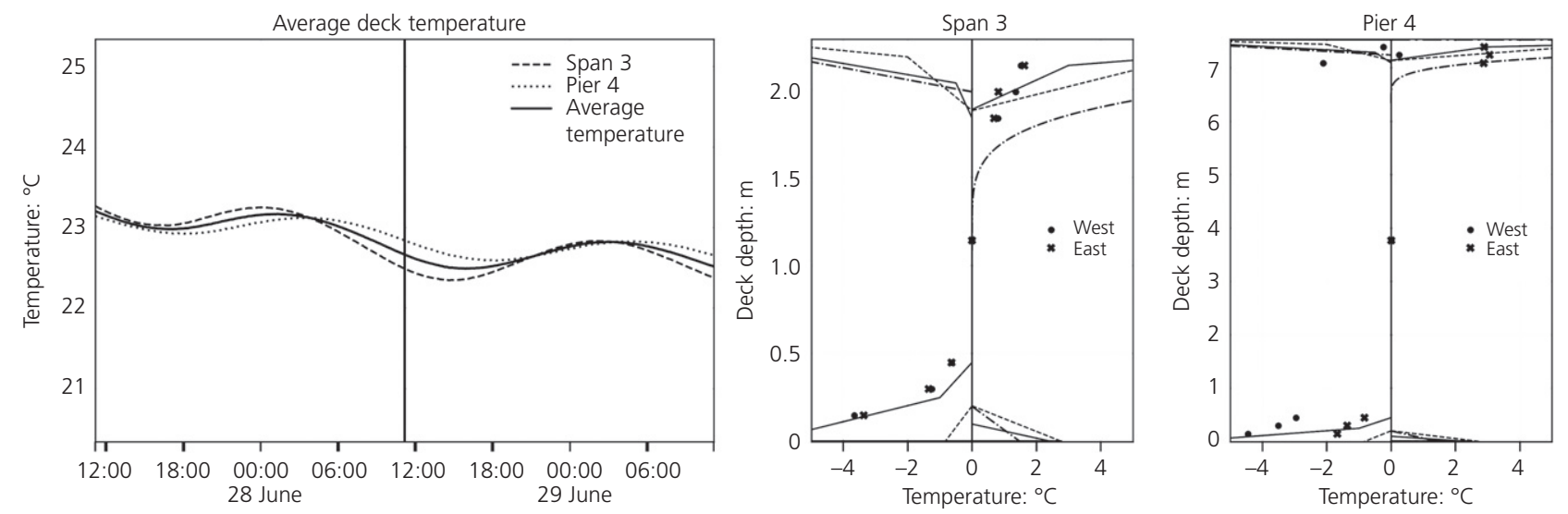

Time and date

Figure 16. Plot showing vertical temperature difference in a period in June 2018

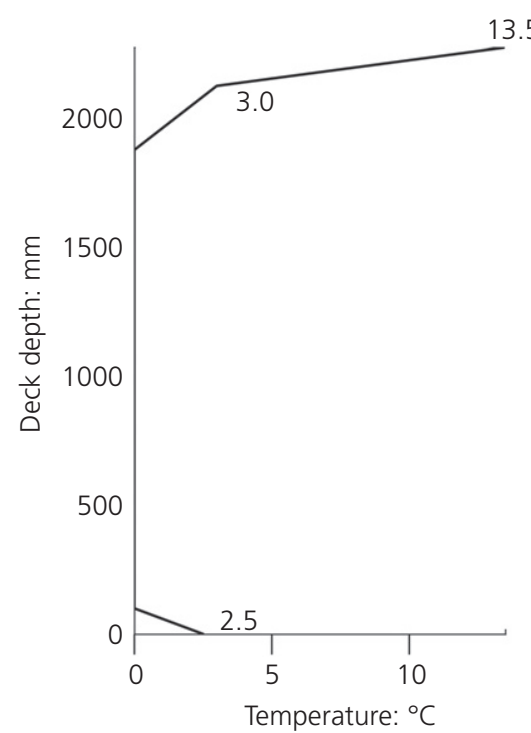

(a)

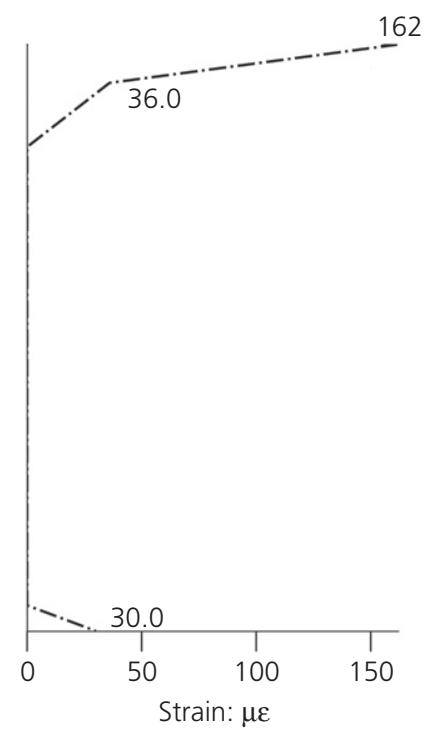

(b)

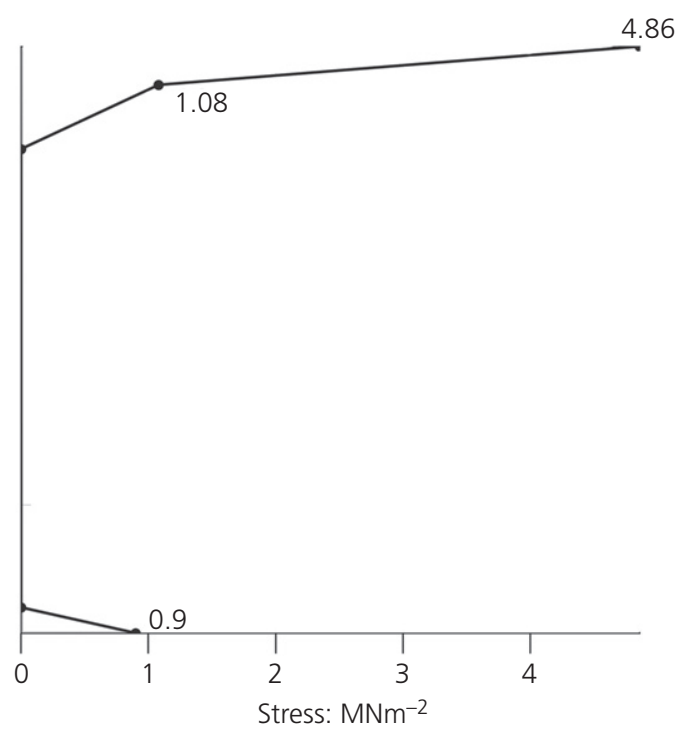

(c)

Figure 17. Temperature effects in span section: (a) 'heating' vertical temperature profile from BS EN 1991-1-5; (b) strains in unrestrained slices; (c) stresses in restrained section

stress gives the resultant stress profile shown in the fourth plot of Figure 18.

The sum of the moments from the flexural component is equal to the resultant moment induced across the cross-sectional area. Therefore, applying this procedure allows calculation of the maximum bending moments induced in a restrained section by each of the design temperature profiles. These maximal moments for both the span and pier sections can be found in Table 5 and are plotted in Figure 19. As would be expected, the positive vertical temperature profiles from each design curve lead to a positive moment, while the negative variation profiles lead to a negative moment. For both sections, the UK design model implies the smallest range of maximal moments, while NZ implies the largest range of maximal moments. The NZ design model gives significantly larger moments compared to the UK and US models, due to its curved positive temperature variation, which covers the 

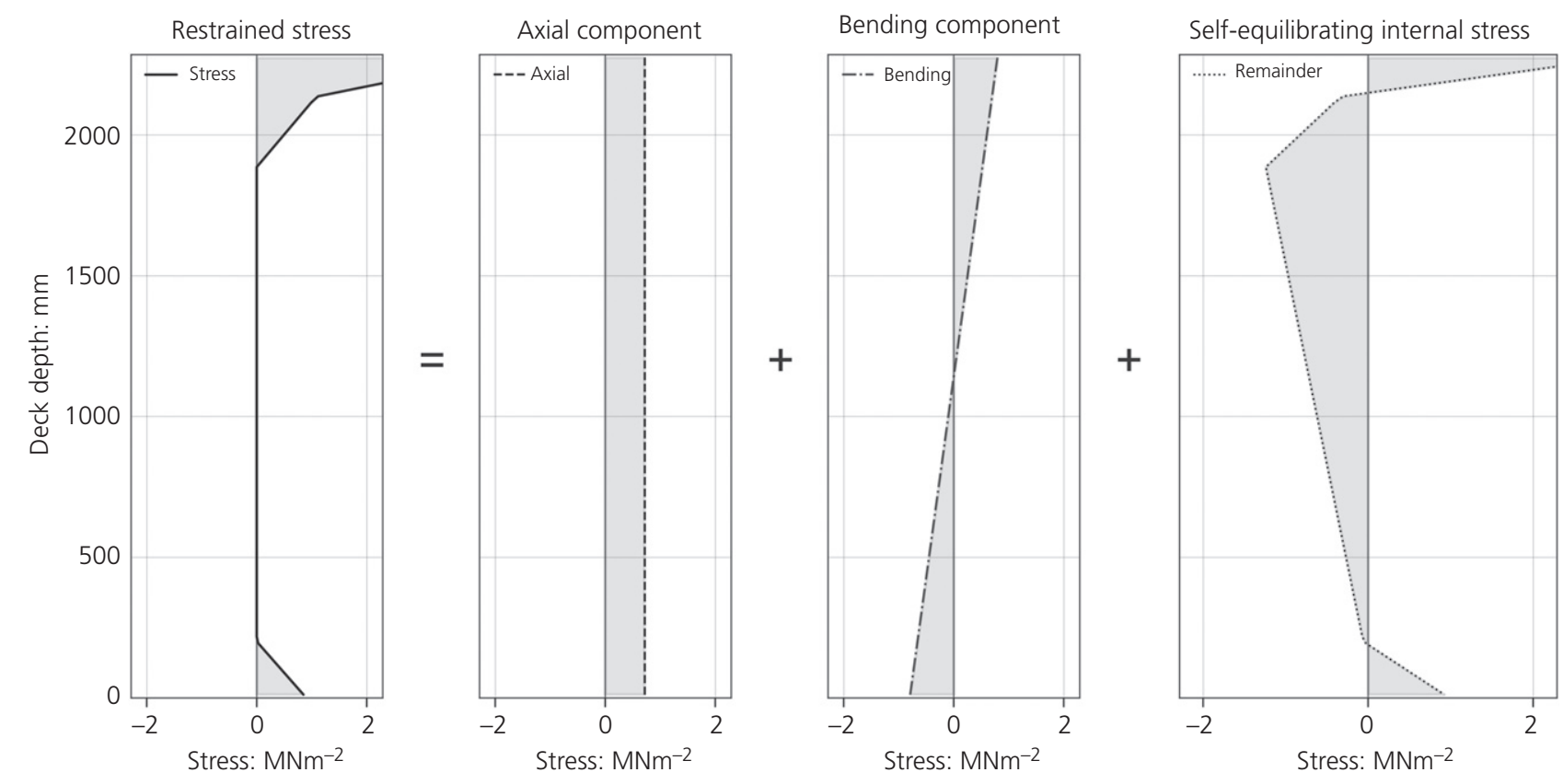

Figure 18. Plot showing the components of the stress in a restrained section induced by the vertical temperature differences of the 'heating' curve in the UK design model

Table 5. Minimum and maximum moments induced in a restrained section by design vertical temperature profiles

\begin{tabular}{|c|c|c|c|c|c|c|}
\hline \multirow{2}{*}{ Section } & \multicolumn{2}{|c|}{ UK } & \multicolumn{2}{|c|}{ US } & \multicolumn{2}{|c|}{ NZ } \\
\hline & Min. & Max. & Min. & Max. & Min. & Max. \\
\hline Span & -0.43 & 3.86 & -2.00 & 6.78 & -3.78 & 12.66 \\
\hline Pier & -5.77 & 17.08 & -8.44 & 28.45 & -16.05 & 67.68 \\
\hline
\end{tabular}

Note: all units in MNm

greatest proportion of the deck depth. For the span section, the NZ maximum moment was $228 \%$ and $86 \%$ larger than the moments calculated from the UK and Aashto models, respectively. In the pier section, the NZ positive was even larger relative to its UK and Aashto counterparts: 296\% and $138 \%$, respectively. The moments induced in the pier section were larger than in the span section, due to the greater crosssectional area.

Applying this process to the measured temperature data enables the calculation of the resultant moments induced in each half of the deck (i.e. east and west) for a given timestamp. A summary of the minimum and maximum moments for each section and whether they exceed the design values is provided in Table 6. Figures 20 and 21 show the resulting plots over the course of the monitoring period, for the span and pier section, respectively. The UK and Aashto maximal moments have been overlaid for reference. The NZ maximal moments were not exceeded and so are excluded from these plots.

For the span section, the data show that the moments in the east and west of the deck are largely similar. A maximum moment of $4.88 \mathrm{MNm}$ was reached in June 2018, and the minimum moment of $-2.71 \mathrm{MNm}$ occurred in December 2017. Both the positive and negative design moments calculated from the UK design model are exceeded, while only the minimum moment for Aashto was exceeded. A notable observation was that the induced moments exceed the lower UK design moments for significant periods of time from December 2017 to February 2018, at times exceeding by over a factor of 5 .

The differences between the east and the west for the pier section are more variable. On average, the data indicate that the moments in the east section are $0.73 \mathrm{MNm}$ higher than in the west section. With regard to exceeding the design moments, it was observed that, in the summer, the induced moments are noticeably more extreme than the UK design moments, and occasionally go just above the US design moments. The maximum moment of $32.76 \mathrm{MNm}$ occurs in June 2018, which was almost double the maximum moment of the UK curve. The UK minimum moment was marginally exceeded in December 2017. 


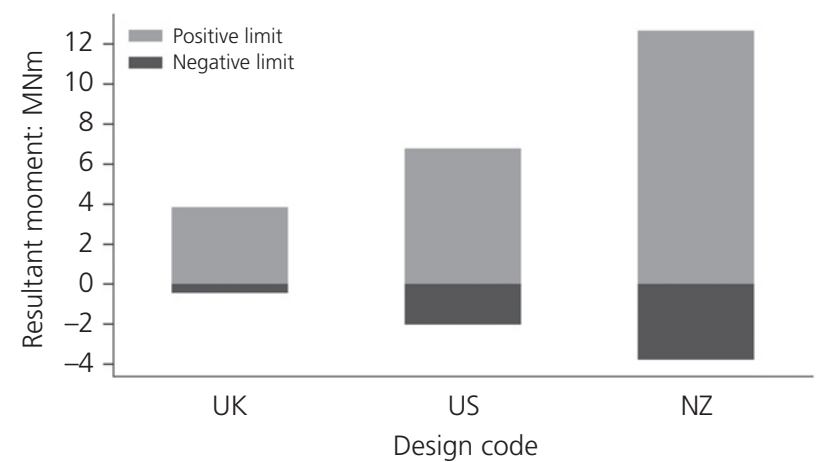

(a)

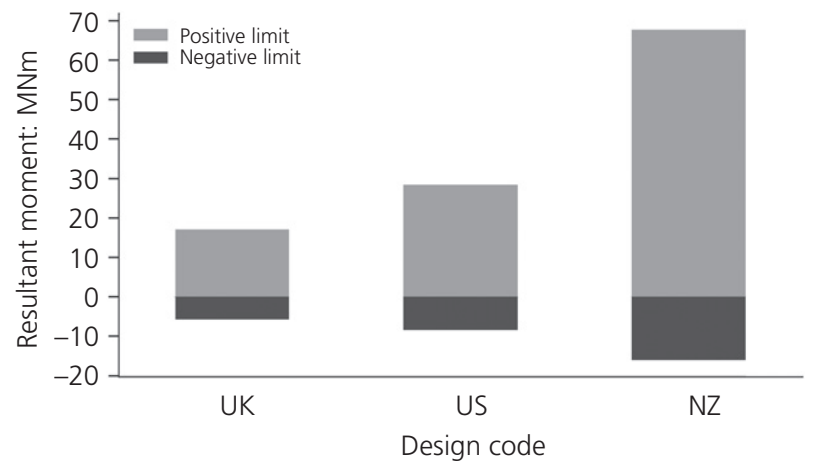

(b)

Figure 19. Positive and negative moment limits implied by the three design curves for: (a) span section; (b) pier section

Table 6. Summary of induced resultant moments calculated from measured temperature data

\begin{tabular}{|c|c|c|c|c|c|c|}
\hline \multirow[b]{2}{*}{ Section } & \multicolumn{3}{|c|}{ Measured: MNm } & \multicolumn{3}{|c|}{ Exceeds design moment } \\
\hline & Min. & Max. & Average & UK & USA & $\mathrm{NZ}$ \\
\hline Span & -2.71 & 4.88 & 0.74 & $\begin{array}{l}\text { Yes: } \\
\text { Min. }(534 \%) \\
\text { Max. }(27 \%)\end{array}$ & $\begin{array}{l}\text { Yes: } \\
\text { Min. (35\%) }\end{array}$ & No \\
\hline Pier & -6.90 & 32.76 & 8.62 & $\begin{array}{l}\text { Yes: } \\
\text { Min. }(19 \%) \\
\text { Max. }(92 \%)\end{array}$ & $\begin{array}{l}\text { Yes: } \\
\text { Max. (15\%) }\end{array}$ & No \\
\hline
\end{tabular}

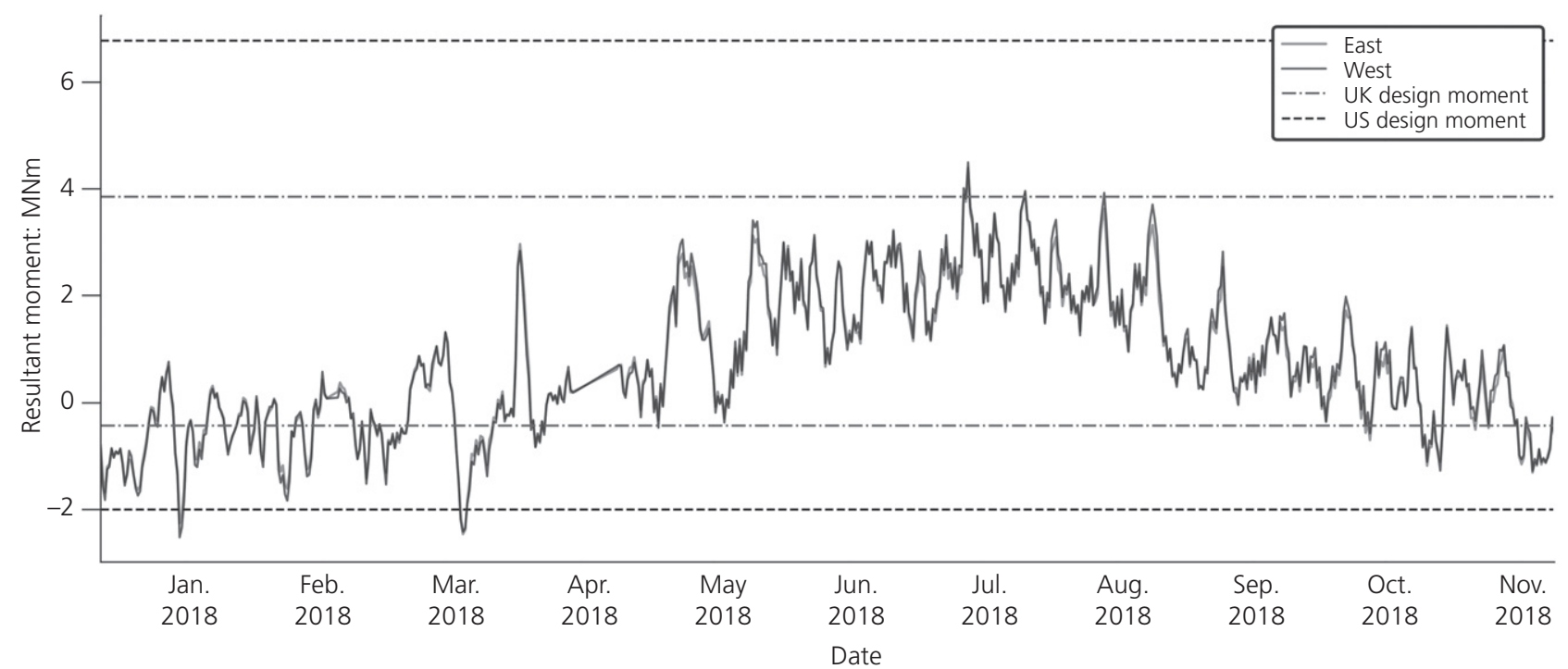

Figure 20. Plot showing the resultant moment for the span section over the course of the monitoring period

The results show that for some load combinations, the design codes may significantly underestimate the peak bending moments in a structure. This could lead to structures being designed with insufficient provision to sustain the moments and displacements that they could experience in service, with a consequential impact on the safety and 


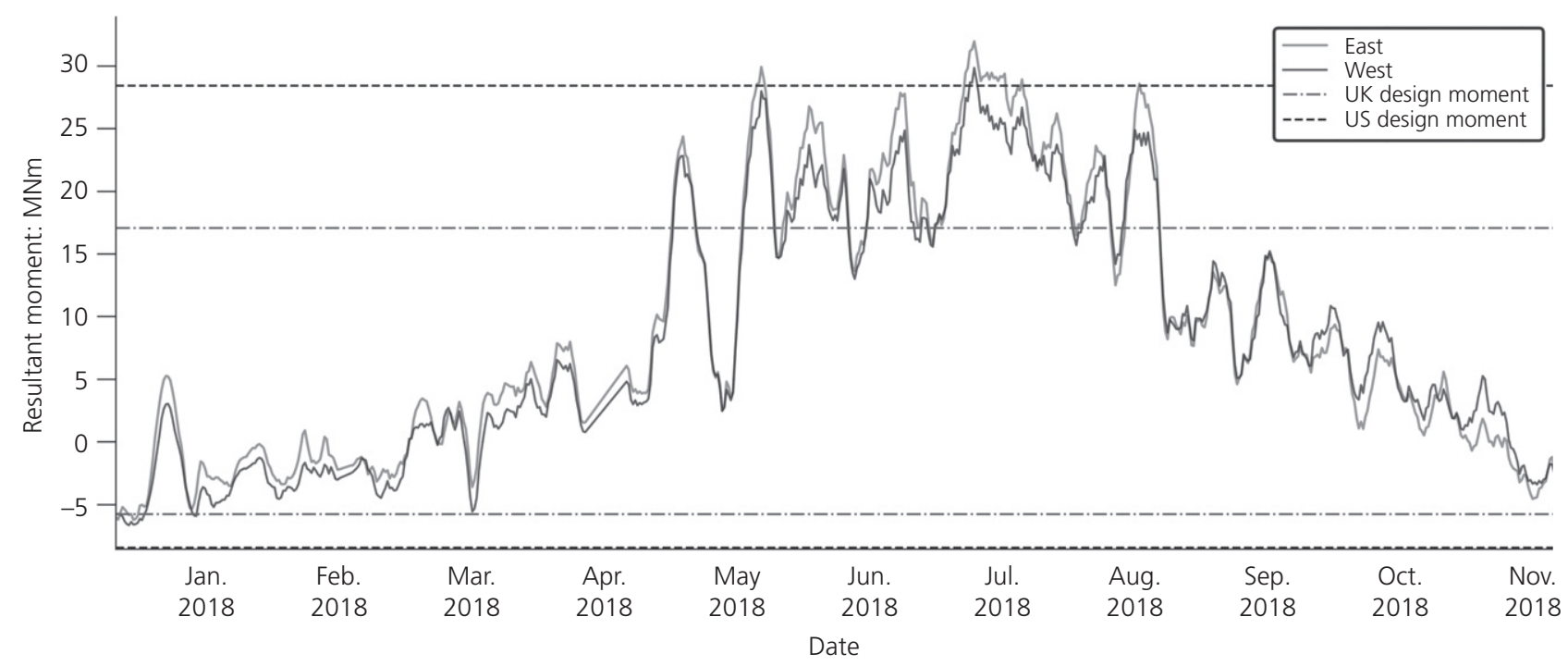

Figure 21. Plot showing the resultant moment for the pier section over the course of the monitoring period

adequacy of those designs. Reassuringly, it is pointed out by Imbsen et al. (1985) that neglecting thermal effects has rarely led to structural damage in bridges in the past, and Barr et al. (2005: p.193) posit that ignored thermal effects are probably counteracted due to the 'conservatism in other components of the nominal, working-stress design procedure'. Another consideration is that these thermal effects are only transient, with the critical thermal profiles only existing for a few hours during extreme weather conditions, and with no lasting long-term effect on the structure's material properties. As such, it may be unlikely that they will co-exist with worstcase loading from other sources and contribute to an exceedance of structural resistances. It is, however, noted that these effects are considered to have been a contributory factor in the dislodgement of the bearings on Waterloo Bridge (Webb and Bennetts, 2020).

\section{Summary and conclusions}

A remote monitoring system was installed on Waterloo Bridge, consisting of 48 temperature sensors and 20 displacement transducers. This paper examines the findings relating to the temperature data collected. Plots were produced to help visualise thermal behaviour, in conjunction with the ambient temperature. As expected, a damped thermal response to the ambient temperature was observed. The thermal model provided by BS EN 1991-1-5 was used to compare with the uniform bridge temperature data collected. The measured data were generally found to fall within the stipulated limits. However, at low temperatures, the data suggest that the minimum deck temperature could be lower than the design relationship provided. This may be taken into consideration for any remedial works, as this design minimum bridge temperature component may be adjusted.

When considering the vertical temperature distribution through the deck, the thermal models provided in the Aashto and NZ design codes were also considered. The worst-case resultant moments were calculated from each of the design models and compared with the moments induced due to the measured temperature variations. This was done for both the span and pier sections. The NZ design model gave significantly larger thermal effects compared to the UK and US models. Conversely, the thermal effects calculated from the UK model were the smallest in magnitude. This relative sizing between the design moments was observed in both sections. However, greater moments are exhibited in the pier section compared to the span section because of its larger cross-sectional area.

The resultant moments implied from the measured temperature profiles significantly exceed the worst-case values predicted by the UK model. In the span section, the minimum moment which occurs in winter was $534 \%$ lower than the UK minimum design moment, while the maximum moment exceeded the maximum design moment by $27 \%$ in the summer. In the pier section, the UK maximum design moment was exceeded by $92 \%$ in the summer, while the minimum design moment was exceeded by $19 \%$ in the winter. For the US design model, the data show that the minimum design moment was exceeded in the span section, while the maximum design moment was surpassed in the pier section. However, these were less exaggerated than the surpassing of the UK design moments. The moments induced from the NZ design model were not exceeded. Overall, 
the monitoring programme on Waterloo Bridge provided valuable information about the structure's in-service thermal behaviour. The thermal data findings, together with the measured movements, will be able to assist any remedial works design. Finally, it should be noted that this paper examines one year of collected data alongside codified design rules that should cover effects over the full service life of the structure: longer-term datasets may reveal different trends.

\section{Acknowledgements}

This paper is published with permission from WCC, who are the bridge owners. The first author would like to acknowledge support from WCC, FM Conway and WSP, as well as from the Engineering and Physical Sciences Research Council (EPSRC) through the National Productivity Investment Fund (grant number EP/R51245X/1). The statements made in this paper do not directly reflect the opinions of the sponsor bodies involved. The first author thanks Dr Nicola Giordano for his valuable advice. Data availability statement: The underlying research data presented in this paper can be made available upon request.

\section{REFERENCES}

Aashto (American Association of State Highway and Transportation Officials) (2012) LRFD bridge design specifications. Aashto, Washington DC, USA.

Aboelseoud MA and Myers JJ (2018) Hybrid composite beam bridge superstructure design considerations for thermal gradient. Journal of Composites for Construction 22(3): 04018005, https://doi.org/ 10.1061/(ASCE)CC.1943-5614.0000838.

Astin D (2017) Waterloo Bridge - structural behaviour and strength. Proceedings of the Institution of Civil Engineers - Bridge Engineering 170(1): 54-64, https://doi.org/10.1680/jbren.15.00006.

Barr PJ, Stanton JF and Oberhard MO (2005) Effects of temperature variations on precast, prestressed concrete bridge girders. Journal of Bridge Engineering 10(2): 186-194, https://doi.org/10. 1061/(ASCE)1084-0702(2005)10:2(186).

Barsotti R and Froli M (2000) Statistical analysis of thermal actions on a concrete segmental box-girder bridge. Structural Engineering International 10(2): 111-116, https://doi.org/10.2749/ 101686600780558036.

Bennetts J, Vardanega PJ, Taylor CA and Denton SR (2016) Bridge data what do we collect and how do we use it? In Transforming the Future of Infrastructure Through Smarter Information: Proceedings of the International Conference on Smart Infrastructure and Construction (Mair RJ, Soga K, Jin Y, Parlikad AK and Schooling JM (eds)). ICE Publishing, London, UK, pp. 531-536.

Bennetts J, Webb GT, Denton SR, Vardanega PJ and Loudon N (2018) Quantifying uncertainty in visual inspection data. In Maintenance, Safety, Risk, Management and Life-Cycle Performance of Bridges: Proceedings of the Ninth International Conference on Bridge Maintenance, Safety and Management (IABMAS 2018) (Powers N, Frangopol DM, Al-Mahaidi R and Caprani C (eds)). CRC Press/Balkema, Leiden, the Netherlands, pp. 2252-2259.

Black W, Moss DS and Emerson M (1976) Bridge Temperatures Derived From Measurement of Movement. Transport and Road Research Laboratory, Crowthorne, UK, LR748.

BSI (2010) BS EN 1991-1-5:2003: Eurocode 1: Actions on structures Part 1-5: General actions - thermal actions. BSI, London, UK.
BSI (2007) NA to BS EN 1991-1-5:2003: UK National Annex to Eurocode 1: Actions on structures. General actions. Thermal actions. BSI, London, UK.

Buckton EJ and Cuerel J (1943) The new Waterloo Bridge. Journal of the Institution of Civil Engineers 20(7): 145-178, https://doi.org/ 10.1680/ijoti.1943.13880.

Dark Sky (2020) Dark Sky API - Overview. Dark Sky, Cambridge, MA, USA. See https:/darksky.net/dev/docs\#data-sources (accessed 09/09/2020).

Elbadry MM and Ghali A (1983) Temperature variations in concrete bridges. Journal of Structural Engineering 109(10): 2355-2374, https://doi.org/10.1061/(ASCE)0733-9445(1983)109:10(2355).

Emerson M (1973) The Calculation of the Distribution of Temperature in Bridges. Transport and Road Research Laboratory, Crowthorne, UK, LR561.

Emerson M (1976a) Bridge Temperatures Estimated from the Shade Temperature. Transport and Road Research Laboratory Crowthorne, Crowthorne, UK, LR696.

Emerson M (1976b) Extreme Values of Bridge Temperatures for Design Purposes. Transport and Road Research Laboratory Crowthorne, Crowthorne, UK, LR744.

Emerson M (1977) Temperature Differences in Bridges: Basis of Design Requirements. Transport and Road Research Laboratory, Crowthorne, UK, LR765.

Hambly EC (1991) Bridge Deck Behaviour, 2nd edn. E \& FN Spon, London, UK.

Hedegaard BD, French CEW, Shield CK, Stolarski HK and Jilk BJ (2013) Instrumentation and modeling of I-35W St. Anthony Falls Bridge. Journal of Bridge Engineering 18(6): 476-485, https://doi.org/ 10.1061/(ASCE)BE.1943-5592.0000384.

Highways England (2017) BD 63/17: Design Manual for Roads and Bridges (DMRB) - Highway Structures: Inspection and Maintenance. Highways England, Guildford, UK.

Historic England (2015) Waterloo Bridge. Historic England, Swindon, UK. See https://historicengland.org.uk/listing/the-list/listentry/1275000 (accessed 09/09/2020).

Imbsen R and Vandershaf D (1984) Thermal effects in concrete bridge superstructures. In Transportation Research Record 950: Second Bridge Engineering Conference (Kassabian N, Herman S, Kaplan E and Starkey J (eds)). Transportation Research Board of the National Academy of Sciences, Washington, DC, USA, vol. 2, pp. 101-113.

Imbsen RA, Vandershaf DE, Schamber RA and Nutt RV (1985) Thermal Effects in Concrete Bridge Superstructures. National Cooperative Highway Research Program (NCHRP), Washington DC, USA, Report 276.

Kim W and Laman JA (2010) Integral abutment bridge response under thermal loading. Engineering Structures 32(6): 1495-1508, https://doi.org/10.1016/j.engstruct.2010.01.004.

Kim SH, Park SJ, Wu J and Won JH (2015) Temperature variation in steel box girders of cable-stayed bridges during construction. Journal of Constructional Steel Research 112: 80-92, https://doi.org/10.1016/ j.jcsr.2015.04.016.

Kong B, Cai CS and Kong X (2013) Thermal behaviors of concrete and steel bridges after slab replacements with GFRP honeycomb sandwich panels. Engineering Structures 56: 2041-2051, https://doi.org/10.1016/j.engstruct.2013.08.024.

Krkoška L and Moravčík M (2015) The analysis of thermal effect on concrete box girder bridge. Procedia Engineering 111: 470-477, https://doi.org/10.1016/j.proeng.2015.07.118.

Lee JH (2012) Investigation of extreme environmental conditions and design thermal gradients during construction for prestressed concrete bridge girders. Journal of Bridge Engineering 
17(3): 547-556, https://doi.org/10.1061/(ASCE)BE.1943-5592. 0000277.

Lucas JM, Berred A and Louis C (2003) Thermal actions on a steel box girder bridge. Proceedings of the Institution of Civil Engineers Structures and Buildings 156(2): 175-182, https://doi.org/10.1680/ stbu.2003.156.2.175.

Lucas JM, Virlogeux M and Louis C (2005) Temperature in the box girder of the Normandy bridge. Structural Engineering International 15(3): 156-165, https://doi.org/10.2749/101686605777963044.

Mortlock J (1974) The Instrumentation of Bridges for the Measurement of Temperature and Movement. Transport and Road Research Laboratory, Crowthorne, UK, LR641.

Nepomuceno DT, Vardanega PJ, Tryfonas T et al. (2021) Viability of off-site inspections to determine bridge defect ratings. In Bridge Maintenance, Safety, Management, Life-Cycle Sustainability and Innovations: Proceedings of the 10th International Conference on Bridge Maintenance, Safety and Management (IABMAS 2020) (Yokota $\mathrm{H}$ and Frangopol DM (eds)). CRC Press, Boca Raton, FL, USA (in press).

NZTA (New Zealand Transport Authority) (2016) Bridge Manual. New Zealand Transport Authority, Wellington, New Zealand.

Peiretti HC, Parrotta JE, Oregui AB, Caldentey AP and Fernandez FA (2014) Experimental study of thermal actions on a solid slab concrete deck bridge and comparison with Eurocode 1. Journal of Bridge Engineering 19(10): 04014041, https://doi.org/10.1061/ (ASCE)BE.1943-5592.0000614.

Potgieter IC and Gamble WL (1983) Response of Highway Bridges to Nonlinear Temperature Distributions. University of Illinois Engineering Experiment Station, University of Illinois at Urbana-Champaign, Champaign, IL, USA, Structural Research Series 505, see http://hdl.handle.net/2142/14113.

Press Office (2018a) March Statistics May Challenge Your Perception. Met Office, Exeter, UK. See https://www.metoffice.gov.uk/aboutus/press-office/news/weather-and-climate/2018/march-statistics (accessed 09/09/2020).

Press Office (2018b) Was Summer 2018 the Hottest on Record? Met Office, Exeter, UK. See https://www.metoffice.gov.uk/about-us/ press-office/news/weather-and-climate/2018/end-of-summer-stats (accessed 09/09 2020).

Priestley MJN (1978) Design of concrete bridges for temperature gradients. ACI Journal Proceedings 75(5): 209-217.

Reynolds JC (1972) Thermal Stresses and Movements in Bridges. MSc thesis, University of Missouri-Rolla, Rolla, MO, USA.

Roberts-Wollman CL, Breen JE and Cawrse J (2002) Measurements of thermal gradients and their effects on segmental concrete bridge.
Journal of Bridge Engineering 7(3): 166-174, https://doi.org/ 10.1061/(ASCE)1084-0702(2002)7:3(166).

Selvakumaran S, Webb GT, Bennetts J, Middleton CR and Rossi C (2019) Waterloo bridge monitoring: comparing measurements from earth and space. In International Conference on Smart Infrastructure and Construction 2019 (ICSIC): Driving Data-Informed DecisionMaking (DeJong MJ, Schooling JM and Viggiani GMB (eds)). ICE Publishing, London, UK, pp. 639-648.

Shoukry SN, Riad MY and William GW (2009) Longterm sensor-based monitoring of an LRFD designed steel girder bridge. Engineering Structures 31(12): 2954-2965, https://doi.org/10.1016/j.engstruct. 2009.07.023.

Skorpen SA, Kearsley EP and Kruger EJ (2018) Measured temperature and shrinkage effects on a $90 \mathrm{~m}$ long integral bridge in South Africa. Proceedings of the Institution of Civil Engineers - Bridge Engineering 171(3): 169-178, https://doi.org/10.1680/ jbren.17.00019.

Skorpen SA, Kearsley EP and Clayton CRI (2019) Structural health monitoring of an integral bridge. In International Conference on Smart Infrastructure and Construction 2019 (ICSIC): Driving Data-Informed Decision-Making (DeJong MJ, Schooling JM and Viggiani GMB (eds)). ICE Publishing, London, UK, pp. 743-749.

SA (Standards Australia) (2017) AS5100.2:2017: Bridge design. Standards Australia, Sydney, Australia.

SI (Status Instruments) (2019) Style 2 Temperature Probe Datasheet. Status Instruments, Tewkesbury, UK. See https://www.status.co. uk/wp-content/uploads/2019/03/3011.pdf (accessed 09/09/2020).

Thepchatri T, Johnson CP and Matlock H (1977) Prediction of Temperature and Stresses in Highway Bridges by a Numerical Procedure using Daily Weather Reports. The University of Texas at Austin, Austin, TX, USA, Research Report Number 23-1.

Webb G and Bennetts J (2020) Waterloo Bridge - from monitoring results to remedial works. In Proceedings of the fib Symposium 2020: Concrete Structures for Resilient Society, Shanghai, China (in press).

Webb GT, Vardanega PJ, Fidler PRA and Middleton CR (2014) Analysis of structural health monitoring data from hammersmith flyover. Journal of Bridge Engineering 19(6): 05014003, https://doi.org/ 10.1061/(ASCE)BE.1943-5592.0000587.

Webb G, Vardanega P and Middleton C (2015) Categories of SHM deployments: technologies and capabilities. Journal of Bridge Engineering 20(11): 04014118, https://doi.org/10.1061/(ASCE)BE. 1943-5592.0000735.

WSP (2017) Waterloo Bridge Monitoring: Technical Specification. WSP Ltd, London, UK.

\section{How can you contribute?}

To discuss this paper, please email up to 500 words to the editor at journals@ice.org.uk. Your contribution will be forwarded to the author(s) for a reply and, if considered appropriate by the editorial board, it will be published as discussion in a future issue of the journal.

Proceedings journals rely entirely on contributions from the civil engineering profession (and allied disciplines). Information about how to submit your paper online is available at www.icevirtuallibrary.com/page/authors, where you will also find detailed author guidelines. 